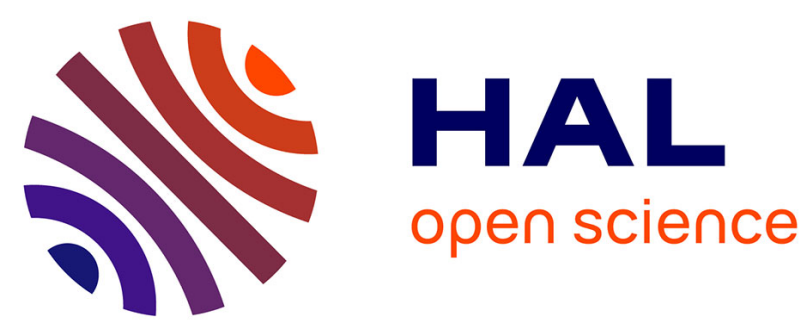

\title{
Class III myosins shape the auditory hair bundles by limiting microvilli and stereocilia growth.
}

Andrea Lelli, Vincent Michel, Jacques Boutet de Monvel, Matteo Cortese, Montserrat Bosch-Grau, Asadollah Aghaie, Isabelle Perfettini, Typhaine Dupont, Paul Avan, Aziz El-Amraoui, et al.

\section{To cite this version:}

Andrea Lelli, Vincent Michel, Jacques Boutet de Monvel, Matteo Cortese, Montserrat Bosch-Grau, et al. Class III myosins shape the auditory hair bundles by limiting microvilli and stereocilia growth.. Journal of Cell Biology, 2016, 212 (2), pp.231-44. 10.1083/jcb.201509017 . pasteur-01317988

\section{HAL Id: pasteur-01317988}

\section{https://hal-pasteur.archives-ouvertes.fr/pasteur-01317988}

Submitted on 19 May 2016

HAL is a multi-disciplinary open access archive for the deposit and dissemination of scientific research documents, whether they are published or not. The documents may come from teaching and research institutions in France or abroad, or from public or private research centers.
L'archive ouverte pluridisciplinaire HAL, est destinée au dépôt et à la diffusion de documents scientifiques de niveau recherche, publiés ou non, émanant des établissements d'enseignement et de recherche français ou étrangers, des laboratoires publics ou privés.

\section{(1)(1) $\$(0)$}

Distributed under a Creative Commons Attribution - NonCommercial - ShareAlikel 4.0 


\title{
Class III myosins shape the auditory hair bundles by limiting microvilli and stereocilia growth
}

\author{
Andrea Lelli, 1,2,3 Vincent Michel, 1,2,3* Jacques Boutet de Monvel, 1,2,3* Matteo Cortese, 1,2,3 \\ Montserrat Bosch-Grau, 1,2,3 Asadollah Aghaie, 1,2,3,4 Isabelle Perfettini, 1,2,3 Typhaine Dupont, 1,2,3 \\ Paul Avan, ${ }^{5}$ Aziz El-Amraoui, $1,2,3 * *$ and Christine Petit ${ }^{1,2,3,4,6 * *}$ \\ 'Unité de Génétique et Physiologie de l'Audition, Institut Pasteur, 75724 Paris, Cedex 15, France \\ ¿Unité Mixte de Recherche UMRS 1 120, Institut National de la Santé et de la Recherche Médicale, 75015 Paris, France \\ 3Sorbonne Universités, Université Pierre et Marie Curie (UPMC Paris VII), Complexité du Vivant, 75005 Paris, France \\ ${ }^{4}$ Syndrome de Usher et Autres Atteintes Rétino-Cochléaires, Institut de la Vision, 75012 Paris, France \\ 5 Laboratoire de Biophysique Sensorielle, Faculté de Médecine, Université d'Auvergne; Biophysique Médicale, Centre Jean Perrin, 63000 Clermont-Ferrand, France \\ ${ }^{6}$ Collège de France, 75005 Paris, France
}

The precise architecture of hair bundles, the arrays of mechanosensitive microvilli-like stereocilia crowning the auditory hair cells, is essential to hearing. Myosin Illa, defective in the late-onset deafness form DFNB30, has been proposed to transport espin-1 to the tips of stereocilia, thereby promoting their elongation. We show that Myo3a-/-Myo3b-/- mice lacking myosin IIla and myosin IIIb are profoundly deaf, whereas Myo3a-cKO Myo3b-/- mice lacking myosin IIlb and losing myosin Illa postnatally have normal hearing. Myo3a-/-Myo3 $\mathrm{b}^{-/-}$cochlear hair bundles display robust mechanoelectrical transduction currents with normal kinetics but show severe embryonic abnormalities whose features rapidly change. These include abnormally tall and numerous microvilli or stereocilia, ungraded stereocilia bundles, and bundle rounding and closure. Surprisingly, espin-1 is properly targeted to $\mathrm{Myo} \mathrm{a}^{-/-} \mathrm{Myo} 3 \mathrm{~b}^{-/-}$stereocilia tips. Our results uncover the critical role that class III myosins play redundantly in hair-bundle morphogenesis; they unexpectedly limit the elongation of stereocilia and of subsequently regressing microvilli, thus contributing to the early hair bundle shaping.

\section{Introduction}

Hearing critically depends on the correct shaping of hair bundles at the apical surfaces of cochlear hair cells, the auditory sensory cells. Cochlear hair bundles contain three rows of actin-filled stereocilia of increasing heights, forming a regular staircase pattern. This architecture ensures the effective gating of mechanoelectrical transduction (MET) channels located at the tips of the stereocilia in the short and middle rows (Beurg et al., 2009). The cochlea contains two types of hair cells, the inner hair cells (IHCs) and the outer hair cells (OHCs), with distinct "U"-like and "V"-like hair bundle shapes, respectively. The IHCs are the genuine sensory cells that convert sound-induced oscillations of their hair bundles into electrical signals transmitted to primary auditory neurons, whereas the OHCs are mechanical effectors involved in the amplification of cochlear vibrations in response to sound (Fettiplace and Kim, 2014). Both the mechanical and geometric characteristics of the hair bundles determine their

*V. Michel and J. Boutet de Monvel contributed equally to this paper.

**A. El-Amraoui and C. Petit contributed equally to this paper.

Correspondence to Christine Petit: christine.petit@pasteur.fr; or Aziz El-Amraoui: aziz.el-amraovi@pasteur.fr

Abbreviations used in this paper: $A B R$, auditory brainstem response; DPOAE, distortion-product otoacoustic emission; E, embryonic day; IHC, inner hair cell; MET, mechanoelectrical transduction; MORN, membrane occupation and recognition nexus; $\mathrm{OHC}$, outer hair cell; $\mathrm{P}$, postnatal day; SPL, sound pressure level; USH, Usher syndrome. response to sound-induced deflecting forces and the frequency tuning properties of this response. Accordingly, the number, lengths, widths, and positions of stereocilia vary in a precisely controlled manner along the cochlea, to ensure the high sensitivity and sharp frequency selectivity of the MET response. The stereocilia are filled with a regular ("paracrystalline") array of parallel actin filaments, tightly bundled by actin cross-linking proteins such as fascins, fimbrins, and espins (Tilney et al., 1980; Shin et al., 2013). These filaments are continuous from the base to the tips of the stereocilia, and uniformly polarized with their barbed (polymerizing) ends located at the tips and their pointed (depolymerizing) ends at the bases. The parallel F-actin core tapers at its base and terminates in a rootlet, a dense and thinned F-actin bundle that anchors each stereocilium to the underlying F-actin-rich cuticular plate of the hair cell apical surface (Furness et al., 2008; Kitajiri et al., 2010).

Mutations in several genes encoding unconventional myosins cause various forms of deafness in humans and mice and have revealed the critical roles of these motor proteins in hair bundle development and maintenance. One of these myosins,

C) 2016 Lelli et al. This article is distributed under the terms of an Attribution-NoncommercialShare Alike-No Mirror Sites license for the first six months after the publication date (see http://www.rupress.org/terms). After six months it is available under a Creative Commons License (Attribution-Noncommercial-Share Alike 3.0 Unported license, as described at http://creativecommons.org/licenses/by-nc-sa/3.0//. 
myosin $\mathrm{XVa}$, is located at the tips of the stereocilia and forms a complex with the PDZ domain-containing protein whirlin and the actin regulatory protein Eps8, whose disruption causes stereocilia to be abnormally short at postnatal stages (Probst et al., 1998; Delprat et al., 2005; Manor et al., 2011). Myosin VIIa, defects of which cause Usher syndrome type I (USH1; Weil et al., 1995), forms a complex with other USH1 proteins (cadherin-23, protocadherin-15, harmonin, and Sans), which is required for the cohesiveness of the growing hair bundle (Petit and Richardson, 2009). Mutant mice lacking myosin VIIa have fragmented hair bundles, and the stereocilia of the tallest row are abnormally long (Gibson et al., 1995; Mburu et al., 1997; Boëda et al., 2002; Lefèvre et al., 2008). The hair bundle also contains myosin VI, whose absence causes a defective tapering of the basal part of the stereocilia (Self et al., 1999). Finally, biallellic mutations in the gene encoding myosin IIIa, MYO3A, cause a late-onset form of deafness, DFNB30 (Walsh et al., 2002). This myosin has been localized to the stereocilia tips in IHCs and OHCs. In newborn rats, myosin IIIa has a "thimble-like" distribution, forming a ring around the tips of the stereocilia (Schneider et al., 2006). When overexpressed in HeLa cells (Les Erickson et al., 2003) and in hair cells of cultured auditory organs (Schneider et al., 2006), a GFP-myosin IIIa fusion protein localizes at the tips of the filopodia and stereocilia. Furthermore, when myosin IIIa and the F-actin bundling and ankyrin repeat-containing protein espin- 1 are both overexpressed in hair cells, they concentrate at the tips of the stereocilia, and the latter elongate (Salles et al., 2009). Myosin IIIa has been shown to transport espin-1 to the tips of filopodia in COS-7 cells, through the binding of its conserved tail homology domain, 3THDI, to the ankyrin repeat domain of espin-1, thereby providing a plausible mechanism by which myosin IIIa could promote F-actin polymerization in filopodia and stereocilia (Salles et al., 2009).

A mouse model of DFNB30, carrying a nonsense mutation of $M y o 3 a\left(M y o 3 a^{K I / K I}\right)$ in the motor head coding region, has been engineered (Walsh et al., 2011). These mutant mice display hearing loss starting around 2.5 mo of age, along with gradual hair cell degeneration past $8 \mathrm{mo}$. Myosin IIIb, the shorttail vertebrate class III myosin paralog, lacks an actin-binding domain on its tail, which prevents this myosin from reaching the tips of filopodia by itself (Merritt et al., 2012; Mecklenburg et al., 2015). Yet myosin IIIb has a distribution similar to that of myosin IIIa in the hair bundle (Merritt et al., 2012). It has been shown to reach stereocilia tips by an espin-1-dependent mechanism, in which espin-1, bound to the 3THDI domain of myosin IIIb, would act as a "crutch," providing the tail of this myosin with the actin-binding activity it intrinsically lacks (Merritt et al., 2012).

We observed the presence of myosins IIIa and IIIb in the stereocilia of mouse cochlear hair cells as early as embryonic day 16.5 (E16.5). This raised the possibility that these two myosins have important functions in the early stages of hair bundle development, concealed by their hypothesized redundant activity. To address this issue, we analyzed mouse mutants carrying a deletion of Myo3a $\left(\right.$ Myo3a $\left.^{-/-}\right)$, Myo3b $\left(\right.$Myo3b $\left.^{-/-}\right)$, or both $\left(\mathrm{Myo3a}^{-/-} \mathrm{Myo3b}^{-/-}\right)$or displaying conditional postnatal inactivation of Myo3a (Myo3a-cKO) or such a deletion with a concomitant full deletion of Myo3b (Myo3a-cKO $\mathrm{Myo}^{-/-}$). Our analyses revealed the critical role of class III myosins in the early patterning of cochlear hair bundles. They are required in the control of the growth process underlying the formation of the cochlear hair bundle, by unexpectedly restraining, rather than promoting, the elongation of the stereociliary F-actin cores.

\section{Results}

Myo3a-/-Myo3 $b^{-/-}$mice are profoundly deaf We first assessed auditory function in $\mathrm{Myo} \mathrm{a}^{-/-}$and $\mathrm{Myo} \mathrm{b}^{-/-}$ mice by measuring the thresholds of auditory brainstem responses (ABRs), which monitor the electrical response of the auditory pathway to brief sound stimuli, using pure tones of frequencies from 10 to $32 \mathrm{kHz}$. We tested $\mathrm{OHC}$ function by recording the distortion-product otoacoustic emissions (DPOAEs) elicited by two-tone stimuli (see Materials and methods). At 1 mo, $\mathrm{Myo} \mathrm{a}^{-/-}$mice displayed no appreciable hearing impairment. However, between 2 and 4 mo, their mean ABR thresholds at 10,15 , and $20 \mathrm{kHz}$ (but not at $32 \mathrm{kHz}$ ) were 8 to $20 \mathrm{~dB}$ higher than those of their heterozygous $\left(\mathrm{Myo3a}^{+/-}\right)$littermates and wild-type mice used as controls $(\mathrm{P}<0.03$ for all comparisons; Fig. 1 A). Their DPOAE thresholds and amplitudes did not differ from those of control mice of the same ages (2-4 mo, $\mathrm{P}>0.1$; Fig. $1 \mathrm{~B}$ ), suggesting that $\mathrm{OHC}$ function was not impaired. Together, these results are consistent with late-onset, mild hearing loss in $M y o 3 a^{-/-}$mice, reminiscent of the hearing loss in Myo3a ${ }^{K I / K I}$ mice (Walsh et al., 2011). In contrast, the ABR thresholds and the DPOAE thresholds and amplitudes of $M y o 3 b^{-l-}$ mice measured between 2 and 4 mo showed no statistically significant difference compared with those of control mice ( $\mathrm{P}>0.1$; Fig. $1, \mathrm{~A}$ and $\mathrm{B})$.

Unlike $\mathrm{Myo}^{-1-}$ and $\mathrm{Myo}^{-1} \mathrm{~b}^{-/-}$mice, $\mathrm{Myo}^{-/-} \mathrm{Myo}^{-1-}$ mice were profoundly deaf at $1 \mathrm{mo}$, with $\mathrm{ABR}$ thresholds exceeding 90-dB sound pressure level (SPL) at all frequencies tested $\left(10,15,20\right.$, and $32 \mathrm{kHz} ; \mathrm{P}<10^{-4}$; Fig. $\left.1 \mathrm{C}\right)$. In addition, their DPOAEs were indistinguishable from the noise background, with DPOAE thresholds above the highest testable stimulus intensity, indicating dysfunctional OHCs (Fig.1 D). The comparison of these results with those obtained for $\mathrm{Myo3a}^{-/-}$and $\mathrm{Myo3}^{-/-}$mice suggested that class III myosins are essential and work redundantly during the development of the auditory system. Consistent with this conclusion, using anti-myosin IIIa and anti-myosin IIIb-specific antibodies, we observed that the two myosins were present in the hair bundles of both IHCs and OHCs as early as E16.5 in mice (Fig. 1, E and F). On postnatal day 7 (P7), myosin IIIa immunostaining was detected at the stereocilia tips in $M y o 3 b^{-/-}$mice (Fig. S1 A); conversely, myosin IIIb immunostaining of the stereocilia tips was detected in $\mathrm{Myo3a}^{-/-}$mice (Fig. S1 B).

\section{Myo3 $b^{-1}$ mice with postnatal inactivation} of Myo3a have normal hearing

We then addressed the possible persistence of compensation between myosin IIIa and myosin IIIb at mature stages. We first generated mice carrying a postnatal deletion of Myo3a (Myo3a$c K O$ mice). Immunostaining for myosin IIIa in Myo3a-cKO cochleas showed a weak signal persisting at the tips of IHC and $\mathrm{OHC}$ stereocilia on P8, which had disappeared entirely by P13 (Fig. 2 A). ABR and DPOAE tests indicated normal hearing of Myo3a-cKO mice at 1 mo. Between 1 and 3 mo, the ABR thresholds of these mice increased significantly (by 20-44 dB) in comparison with those of control mice for each frequency tested between 10 and $32 \mathrm{kHz}\left(\mathrm{P}<10^{-2}\right.$; Fig. $\left.2 \mathrm{~B}\right)$. At these ages, the ABR thresholds of $M y o 3 a-c K O$ mice were also 

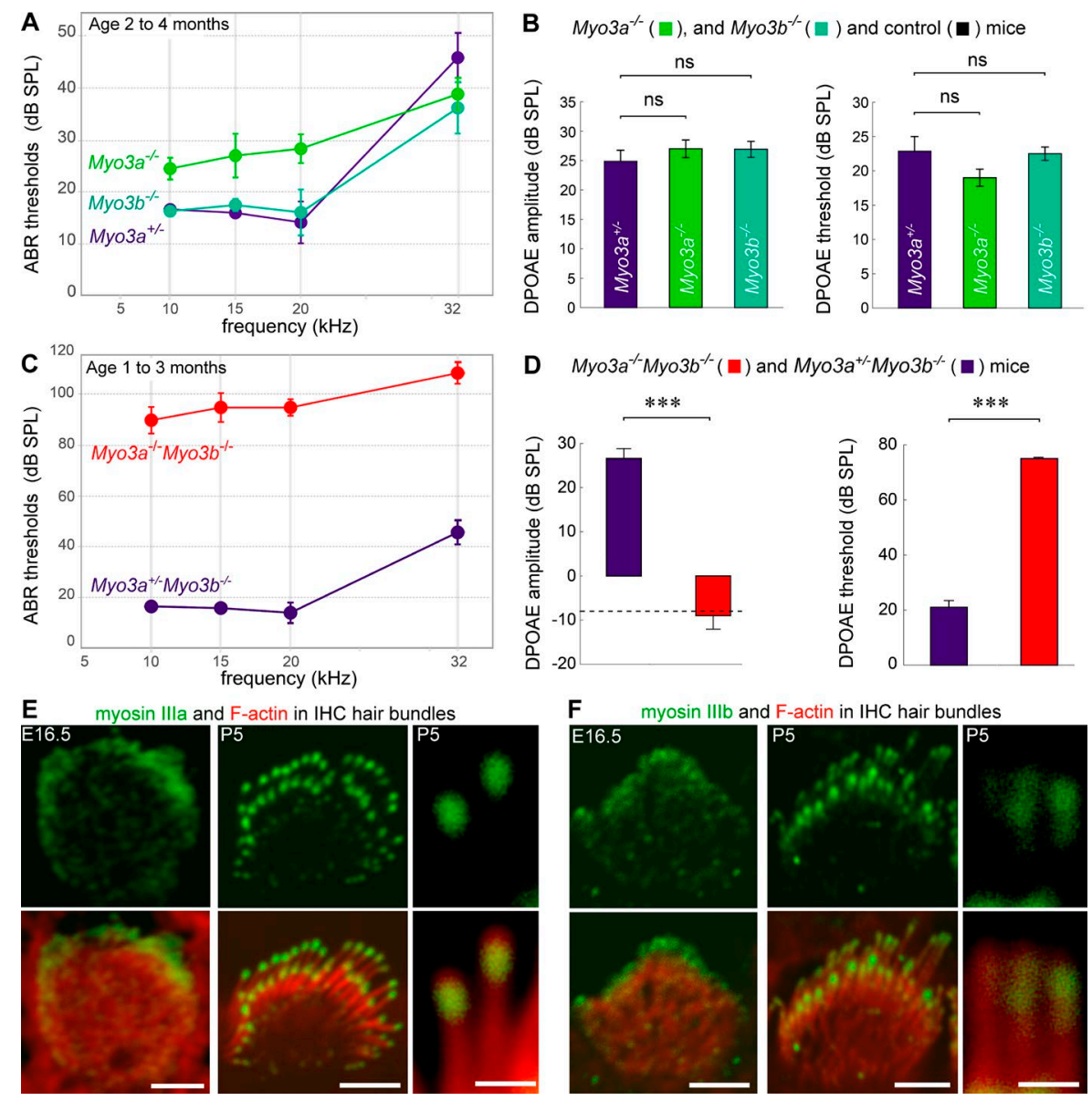

Figure 1. Hearing sensitivity in myosin III-deficient mice and distribution of class III myosins in the hair bundle. (A and B) ABR thresholds for pure tones between 5 and 32 $\mathrm{kHz}(\mathrm{A})$, and DPOAE amplitudes and thresholds for primary tone frequencies $f_{1}=15 \mathrm{kHz}$ and $f_{2}=1.2 f_{1}(\mathrm{~B})$ in $\mathrm{Myo}^{2} \mathrm{a}^{+/-}, \mathrm{Myo}^{-1 /-}$, and $M y o 3 b^{-/-}$mice. Plotted curves represent averages over the period 2-4 mo. (C and D) $A B R$ thresholds (C) and DPOAE amplitudes and thresholds for the same primary frequencies (D) in Myo3a+/-Myo3b-/- (dark purple) and $\mathrm{Myo}^{-} \mathrm{a}^{-/-} \mathrm{Myo} 3 \mathrm{~b}^{-/-}$(red) mice. Averages (mean \pm SEM) are plotted over the age period 1-3 mo. The dashed line indicates the noise floor of the microphone $(-8 \mathrm{~dB} S \mathrm{SP})$; $0 \mathrm{~dB} S \mathrm{SP}$ marks a sound pressure level at the human hearing threshold at $1 \mathrm{kHz}(20 \mu \mathrm{Pa})$. Asterisks indicate significance $1^{* * *}, P<0.001$; ns, nonsignificant difference; Welsch's $t$ test). ( $E$ and F) Myosin IIla (E) and myosin IIIlb (F) in F-actin-labeled (red) $\mathrm{IHC}$ hair bundles. On E 16.5, both myosins display robust expression in the stereocilia. On P5, they are located at the stereocilia apices but excluded from their extreme tips (right). Bars: (left and middle) $2 \mu \mathrm{m}$; (right) $500 \mathrm{~nm}$. significantly higher (by $18-28 \mathrm{~dB}$ ) than those of $\mathrm{Myo}^{-1-}$ mice $(\mathrm{P}<0.002$ at each frequency), and a difference persisted at 6 mo $(\mathrm{P}=0.02$, comparison across all frequencies). However, as in $\mathrm{Myo3a}^{-1-}$ mice, no change in DPOAE thresholds and amplitudes was detected in $M y o 3 a-c K O$ mice $(\mathrm{P}=0.1$; Fig. $\mathrm{S} 1$ $\mathrm{C})$, indicating normal functioning of the OHCs. Strikingly, the auditory responses of $\mathrm{Myo3a-cKO} \mathrm{Myo}^{-/-}$mice, which lack both myosins IIIa and IIIb at mature stages but retain myosin IIIa during the early postnatal stage, did not differ significantly from those of control mice. These mutant mice had normal ABR thresholds in the 10- to $32-\mathrm{kHz}$ frequency range and normal DPOAE amplitudes up to at least 6 mo (Figs. 2 B and S1 C). This result, combined with the absence of an abnormal auditory phenotype in $M y o 3 b^{-/-}$mice, suggested that the inactivation of Myo3a elicits a deleterious effect of myosin IIIb at mature stages, possibly exacerbated in Myo3a-cKO mice. Altogether, these data revealed that the period during which class III myosins play their most critical roles in the mouse cochlea does not extend beyond the onset of hearing (P12-P14 in mice).

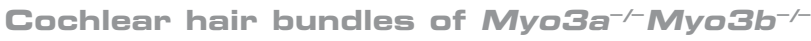 mice have abnormally long stereocilia and show dynamic shape defects during development}

We investigated possible hair bundle defects underlying the deafness of $\mathrm{Myo3a}^{-/-} \mathrm{Myo}^{-/-}$mice by scanning electron microscopy between E16.5 and P9 (Figs. 3, 4, and 5). In the mouse, the morphogenesis of auditory hair bundles starts on $\sim$ E14 near the base of the cochlea and progresses gradually toward its apex (Cotanche and Corwin, 1991; Denman-Johnson and Forge, 1999). Before stereocilia emerge, the apical surface of the hair cell is covered with microvilli similar in size surrounding the centrally positioned kinocilium (Tilney et al., 1992). The kinocilium, a genuine cilium (Flock and Duvall, 1965), controls the initial positioning and polarity of the developing hair bundle (Jones and Chen, 2008; Deans, 2013). Its migration to the lateral side of the apical surface between E14.5 and E17.5 (Lepelletier et al., 2013) initiates a first phase of growth during which the microvilli-like precursors of the stereocilia that are closest to the kinocilium elongate and widen first, forming the tallest stereocilia row, followed by growth of the other rows (Tilney et al., 1992; Kaltenbach et al., 1994). The kinocilium marks the vertex of the hair bundle (Cotanche and Corwin, 1991; Denman-Johnson and Forge, 1999), whose shape and positioning are constrained by the compartmentalization of the asymmetric cell division proteins Par- 6 and $\mathrm{G \alpha i}_{3}$ at the apical surface of the hair cell (Ezan et al., 2013; Tarchini et al., 2013; see also Fig. S2, A and B). By P0, the IHCs and the $\mathrm{OHCs}$ harbor a regular polarized staircase formed by 5-10 rows of stereocilia of graded heights, with typical U and V shapes, respectively (Fig. 3, A and B).

A second phase of selective stereocilia development extends up to the first two postnatal weeks, during which the three tallest stereocilia rows continue to widen and change length until they reach their mature size (in the mouse cochlea, they shorten except in the most apical cochlear regions, where they elongate; Sekerková et al., 2011), whereas the remaining microvilli regress (Barr-Gillespie, 2015; Fig. 3 B, top). An overall 

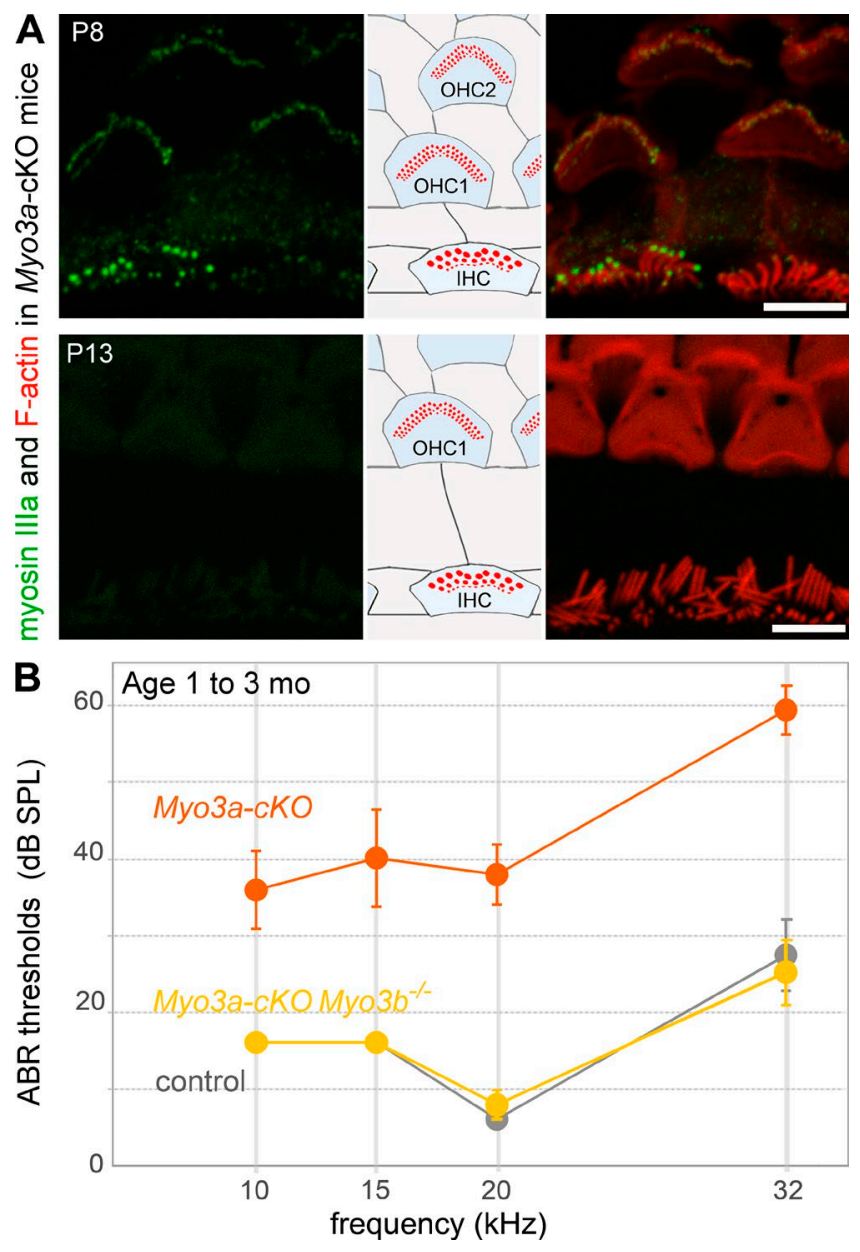

Figure 2. Myosin Illa distribution and hearing sensitivity in Myo3a-cKO mice. (A) Cochleas of Myo3a-cKO mice immunostained with anti-myosin Illa antibodies (green) on P8 and P13. Note the disappearance of myosin Illa from the F-actin-labeled stereocilia (red) on P13. Bars, 5 pm. (B) ABR thresholds of $\mathrm{Myo} \mathrm{a}^{\mathrm{fl} / \mathrm{fl}} \mathrm{Myo} 3 \mathrm{~b}^{-/-}$(controls, gray), Myo3a-cKO (orange), and Myo3a-cKO Myo3b-/- (yellow) mice, averaged over the age period of 1-3 mo (mean \pm SEM).

increase of the spacing between stereocilia accompanies their continuous widening and functional maturation during this phase (Kaltenbach et al., 1994).

Up to birth (P0), the Myo3 $a^{-/-} \mathrm{Myo}^{-/-}$hair bundles displayed a cohesive appearance at all cochlear locations (Fig. 3, $\mathrm{A}$ and $\mathrm{B})$, consistent with the presence of lateral interstereocilia links in these bundles (Fig. S3 A). The position of the kinocilium was normal, and the distributions of Par- 6 and $\mathrm{G \alpha i}_{3}$ displayed characteristic V-shaped compartmentalizations at the apical hair cell surface (Fig. S2, A and B). However, already on E16.5, striking hair bundle abnormalities were visible in both $\mathrm{Myo3a}^{-/-} \mathrm{Myo}^{-/-} \mathrm{IHCs}$ and OHCs. In the mid-to-apical cochlear region, most of the IHCs (81\%), but only $19 \%$ of the OHCs, had seemingly normal U- or V-shaped hair bundles (Fig. 3, B and C). The most notable defect was the presence of misshaped bundles with abnormally long protrusions of apparently ungraded heights (in $8 \%$ of the IHCs and 33\% of the $\mathrm{OHCs}$ ), hereafter referred to as "long amorphous" bundles (Fig. 3, B and C). The remaining hair bundles referred to as "others" (11\% of IHCs and 58\% of OHCs; Fig. 3 C) had also abnormal shapes but harbored stereocilia rows organized in a staircase pattern. Among these, a few $\mathrm{OHC}$ hair bundles $(<5 \%)$ displayed exuberant centrally positioned protrusions of flaccid appearance, up to three times longer than the nearby stereocilia (Fig. 3, B and C).

In P0 Myo3a $a^{-1-} \mathrm{Myo} \mathrm{b}^{-/-}$mice, marked changes of hair bundle shapes had occurred in both IHCs and OHCs. Only $9 \%$ of the IHC bundles were still U-like shaped. The fraction of long amorphous IHC bundles had become predominant $(76 \%)$, whereas the fraction of others remained about the same $(15 \%$; Fig. $3 \mathrm{C}$ ). In contrast, in $\mathrm{P} 0 \mathrm{OHCs}$, long amorphous bundles were no longer present, whereas the fraction of V-like-shaped OHC bundles was only slightly decreased (12\%), and those classified as others had become predominant (88\%; Fig. $3 \mathrm{C}$ ). The most striking abnormalities of the $\mathrm{OHC}$ hair bundles classified as others were a rounding of their shape, accompanied by the occurrence, in $67 \%$ of the $\mathrm{P} 0 \mathrm{OHCs}$, of one or more ectopic "side" rows prolonging the tallest stereocilia row and often closing the hair bundle, which appeared almost circular in some OHCs (Fig. 3, A and B). The exuberant protrusions seen on E16.5 were very rare on $\mathrm{P} 0$ and never observed at later stages (Fig. 3, B and C). On P9, these hair bundle abnormalities had even worsened, affecting all the hair cells. In the mid-toapex of the cochlea, most of the IHCs $(\sim 75 \%)$ harbored long amorphous hair bundles, and $\sim 50 \%$ of the OHC bundles displayed closed or circular shapes. These hair bundles had also lost cohesiveness, some of the $\mathrm{OHC}$ bundles even being fragmented (Fig. 3 B, bottom).

We also measured the mean projected height of the tallest row of stereocilia in the IHCs and OHCs in the mid-to-apex of the cochlea. This height was markedly greater in the P0

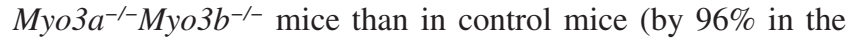
IHCs and by $27 \%$ in the OHCs, $\mathrm{P}<10^{-5}$; Fig. $4 \mathrm{~A}$ and Table 1 ). The height of the tallest stereocilia row remained greater on $\mathrm{P} 9$ in $\mathrm{Myo} \mathrm{a}^{-1-} \mathrm{Myo}^{-1-}$ mice than in control mice, by $60 \%$ for the IHC bundles and by $103 \%$ for the OHC bundles $\left(\mathrm{P}<10^{-3}\right.$; Fig. $4 \mathrm{~A}$ and Table 1). The increased difference in the $\mathrm{P} 9 \mathrm{OHC}$ bundles reflected the fact that the height of the tallest $\mathrm{OHC}$ stereocilia did not change in $\mathrm{Myo3a}^{-/-} \mathrm{Myo3b}^{-/-}$mice between P0 and P9, whereas it decreased by $\sim 36 \%$ in the control mice, as expected (Sekerková et al., 2011; Fig. 4 A).

Therefore, the cochlear hair bundles of $\mathrm{Myo3a}^{-/-} \mathrm{Myo}^{-\mathrm{b}^{-/}}$ mice are affected by major developmental abnormalities of stereocilia heights and hair bundle shape. The rapid developmental changes in these anomalies betray a dynamic instability of the F-actin-rich microvilli and stereocilia during their elongation.

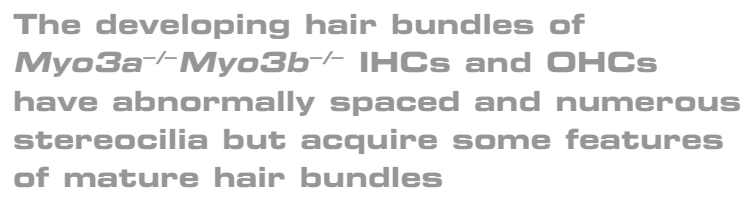

We further characterized the abnormalities of $\mathrm{Myo} \mathrm{a}^{-/-} \mathrm{Myo}^{3 \mathrm{~b}^{-/-}}$ cochlear hair bundles by analyzing the number and spacing of stereocilia within their tallest row and the distance between rows. On $\mathrm{P} 0$, the total number of stereocilia in the tallest row

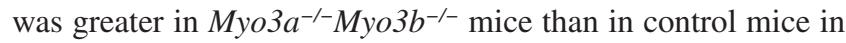
both IHCs and OHCs (by 57\% and 37\%, respectively, in the mid to apex of the cochlea; $\mathrm{P}<10^{-5}$; Fig. $4 \mathrm{~B}$ and Table 1 ). In the IHCs, the density of stereocilia was also markedly higher in Myo3 $a^{-/-} \mathrm{Myo}^{-1-}$ mice within the tallest row and between the three tallest rows (the interstereocilia distances were decreased by $\sim 40 \%$, compared with their values in control mice, in the mid to apex of the cochlea; $\mathrm{P}<10^{-3}$; Fig. $4 \mathrm{~B}$ and Table 1$)$. In 
A

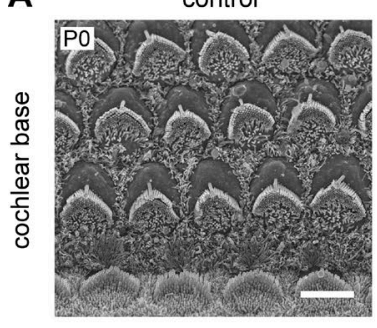

B
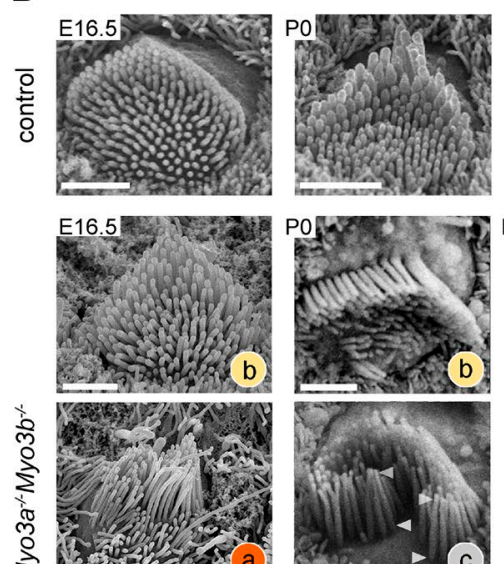

$\stackrel{2}{\Sigma}$

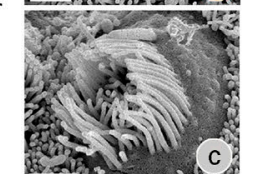

C

Architecture of cochlear hair bundles in $\mathrm{Myo} \mathrm{a}^{--} \mathrm{Myo} 3 \mathrm{~b}^{--}$mice $\mathrm{IHC}$

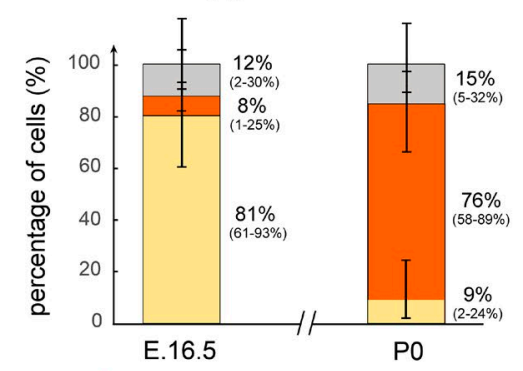

(a) amorphous
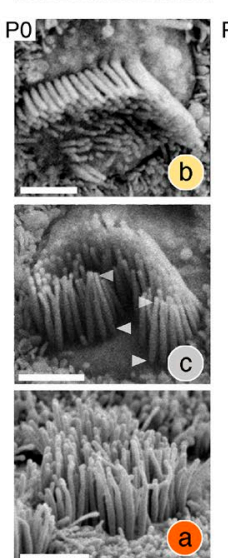

Мyo3a--Myo3 ${ }^{-/-}$
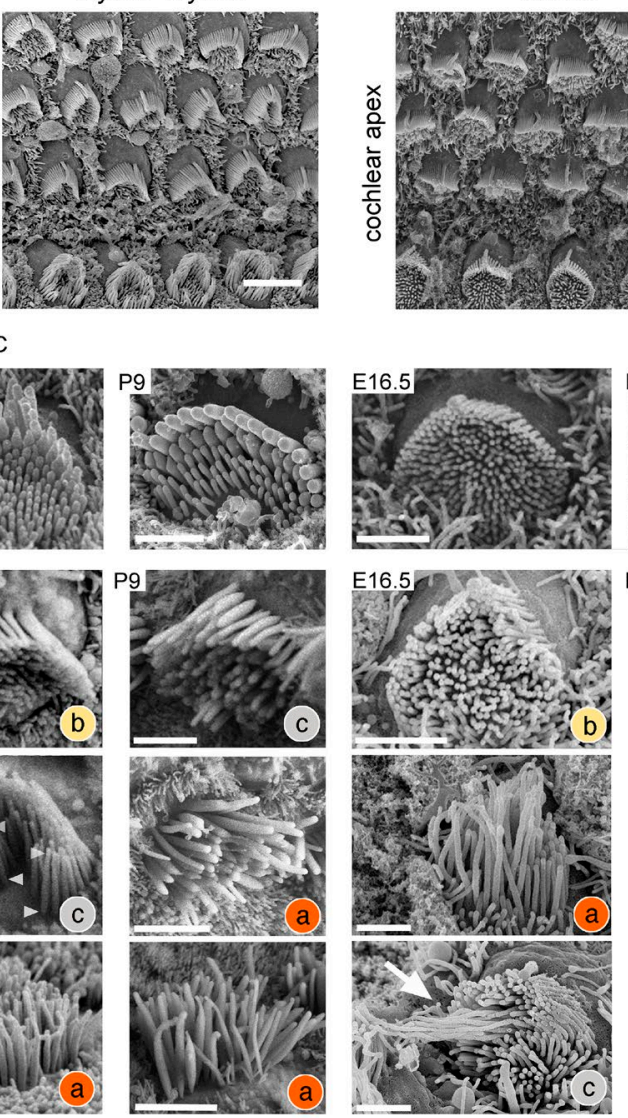

control

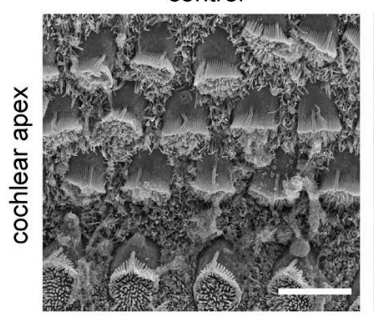

Myо3a $\%$ Myo3b

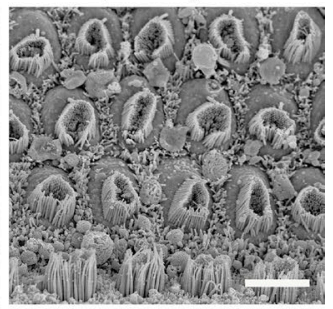

$\mathrm{OHC}$
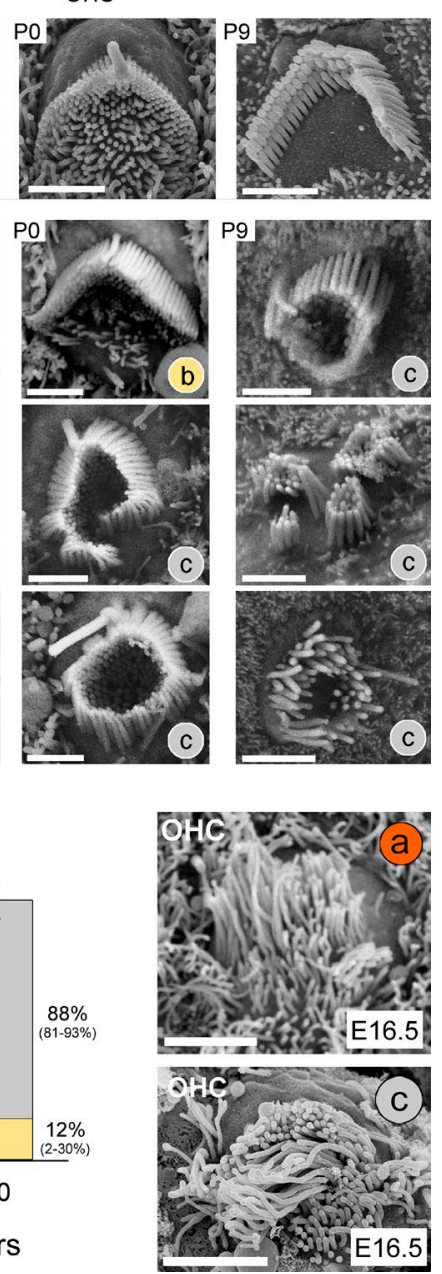

Figure 3. Architecture of cochlear hair bundles in wild-type and $M y{ }^{-3} \mathbf{a}^{-/-}$Myo3b-/- mice. (A) On PO, more pronounced defects are observed at the

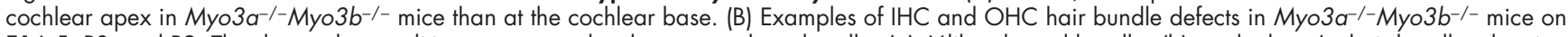
E16.5, PO, and P9. The shape abnormalities are grouped as long amorphous bundles (a), V-like-shaped bundles (b), and others (c; hair bundles showing a well-defined but abnormally shaped staircase of stereocilia, e.g., rounded or closed, or harboring lateral "wings"). An example of central-exuberant protrusions in an $\mathrm{E} 16.5 \mathrm{OHC}$ bundle (arrow) is shown. On PO, a few $\mathrm{IHC}$ bundles displayed base-to-tip tapering of the stereocilia (arrowheads). (C) Fractions of the various categories of hair bundle shape abnormalities in Myo3a-/-Myo3b-/- cochleas, estimated for $26 \mathrm{IHCs}$ and 91 OHCs on E16.5 and for 33 $\mathrm{IHCs}$ and $117 \mathrm{OHCs}$ on PO. 95\% confidence intervals are indicated in parentheses. Bars: (A) $5 \mu \mathrm{m}$; (B and C) $2 \mu \mathrm{m}$.

the $\mathrm{OHCs}$, the mean interstereocilia distance within the tallest row was not significantly altered $(\mathrm{P}>0.1)$, whereas the interrow distance was $\sim 30 \%$ larger in $\mathrm{Myo3a}^{-/-} \mathrm{Myo}^{-/-}$mice than in control mice $\left(\mathrm{P}<10^{-3}\right.$; Fig. $4 \mathrm{~B}$ and Table 1$)$. Notably, between $\mathrm{P} 0$ and $\mathrm{P} 9$, the hair bundles of both $\mathrm{Myo} \mathrm{a}^{-/-} \mathrm{Myo} 3 \mathrm{~b}^{-/-} \mathrm{IHCs}$ and $\mathrm{OHCs}$ displayed a decrease of the number of stereocilia in the tallest row and an overall increase of the interstereocilia distances (within the tallest row and between the three tallest rows; $\mathrm{P}<10^{-4}$; Fig. $4 \mathrm{~B}$ and Table 1). Thus, the cochlear hair bundles of $\mathrm{Myo3a}^{-/-} \mathrm{Myo}^{-/-}$ mice initially contained too many stereocilia, which were in addition too densely packed in the IHCs, but they underwent mor- phological evolutions similar to those seen in the control mice and expected during the normal maturation of cochlear hair bundles.

We extended our analysis to the stereocilia rootlets using immunostaining of the rootlet protein TRIOBP, which allows the visualization of individual rootlets from P1 onwards, shortly after their formation (Kitajiri et al., 2010; Fig. 5 A). In P4 control mice, the TRIOBP-labeled spots in the OHCs or IHCs formed three neat V- or U-shaped rows and were not observed at the emplacement of the occasionally persisting central microvilli (Fig. 5, A and B). In contrast, in IHCs of $M y o 3 a^{-/-} M y o 3 b^{-/-}$ mice, the TRIOBP spots were abnormally numerous, forming 


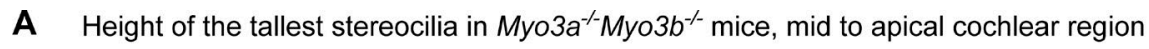
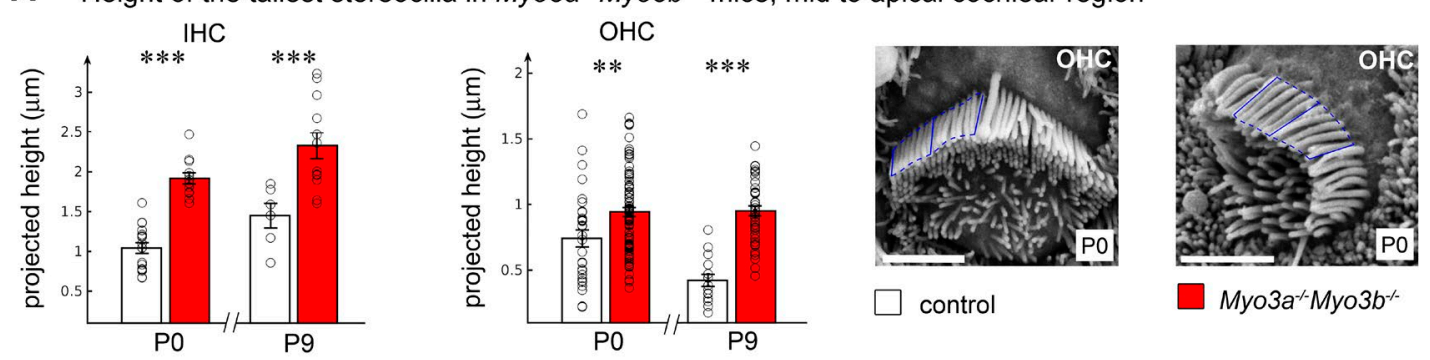

B Number of stereocilia, intra- and inter-row distances between stereocilia in $M y o 3 a^{-1-} M_{y o 3 b^{-1}}$ mice $\mathrm{IHC}$
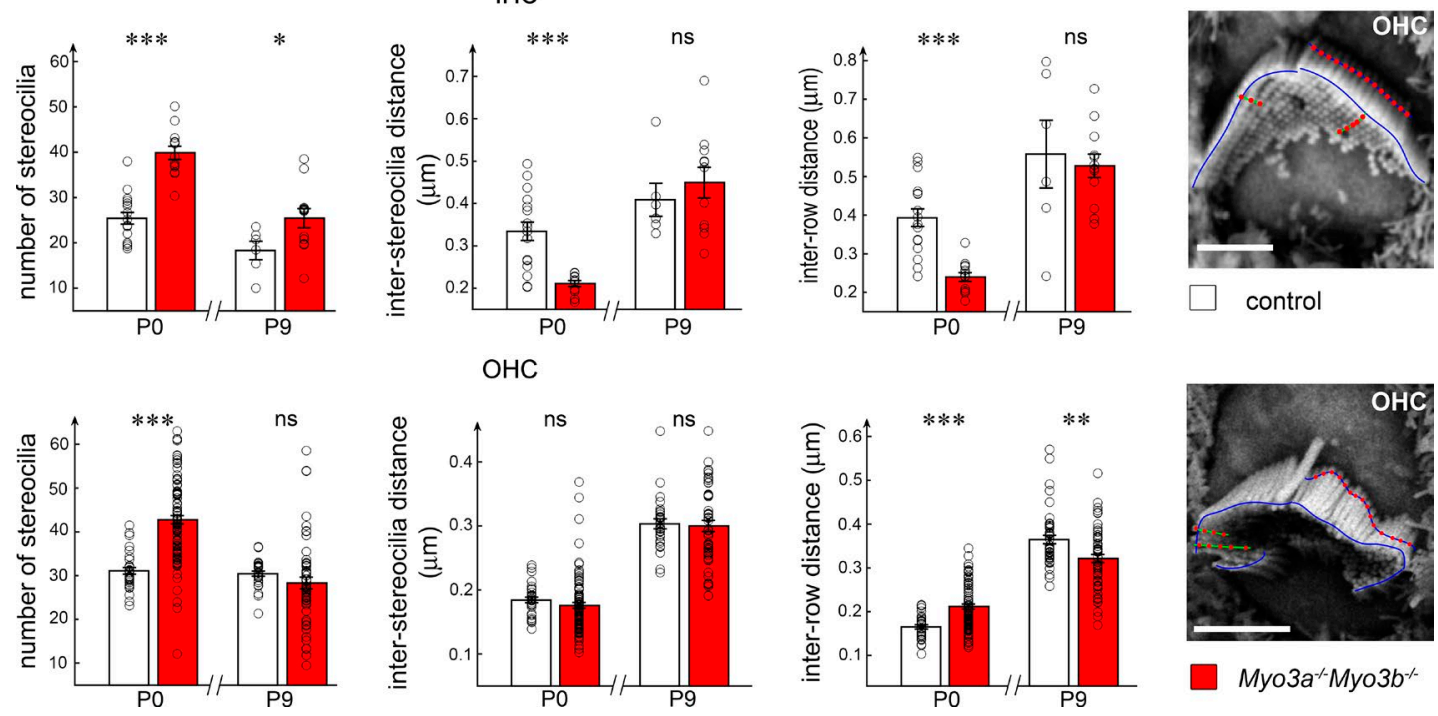

Figure 4. Geometric characteristics of IHC and OHC hair bundles in $\mathrm{Myo3}^{-1-} \mathrm{Myo3b^{-/- }}$ mice. (A) Projected height of the tallest stereocilia row in the IHC and $\mathrm{OHC}$ hair bundles of control and $\mathrm{Myo} \mathrm{a}^{-/-} \mathrm{Myo} 3 \mathrm{~b}^{-/-}$mice, with illustrative PO hair bundles. Mean \pm SEM for bundles with a distinct tallest row (types $\mathrm{b}$ or c) is plotted on PO and P9. (B) The mean number of stereocilia, the interstereocilia distances within the tallest row, and between the three tallest rows are plotted (mean \pm SEM) for PO and P9 mice. Representative hair bundles illustrating the measurements performed, e.g., the interstereocilia distances and the total length of the tallest row of stereocilia (used to estimate the total number of stereocilia) are shown. Cell numbers for the various characteristics averaged are given in Table 1. Bars, $2 \mu \mathrm{m}$. Asterisks indicate significance as in Table 1.

up to 10 rows organized into a roughly hexagonal mosaic in long amorphous hair bundles; in the OHCs, the TRIOBP spots formed a generally closed pattern (Fig. 5, A and B). These observations suggest that all persisting microvilli, either centrally located in the IHC bundles or at the medial side (opposite to the kinocilium) of the OHC bundles forming "side wings" or closing these bundles, had developed rootlets, indicating their differentiation into mature stereocilia.

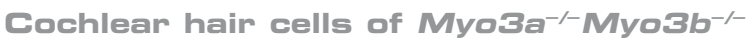

mice display robust MET current responses On the basis of its peculiar thimble-like distribution, enclosing the tips of the stereocilia, it has been suggested that myosin IIIa could adjust the tenting of stereocilia membranes near the tip links and thereby influence MET channel gating including the MET adaptation process (by which a rapid reduction of MET currents occurs during a prolonged mechanical stimulation; Schneider et al., 2006). We addressed this issue by recording MET currents in IHCs and OHCs from the apical third of co-

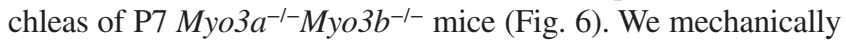
stimulated hair bundles with an approximately normal $\mathrm{V}$ or $\mathrm{U}$ shape in this region (avoiding circular or closed bundles) while recording MET currents by the whole-cell patch-clamp technique (Fig. 6, A and F). Myo3 $a^{-/-} M y o 3 b^{-/-}$hair cells displayed robust
MET current responses, with mean peak amplitudes of $537 \pm 62$ pA for OHCs $(n=11)$ and $710 \pm 122 \mathrm{pA}$ for IHCs $(n=7)$. The averaged peak amplitude of these MET currents was unaltered in the IHCs ( $\mathrm{P}=0.39$, Welsh's $t$ test), whereas it was about halved in the OHCs $\left(\mathrm{P}<10^{-4}\right)$, compared with the MET current amplitudes of control IHCs and OHCs, respectively. The sensitivity of the MET response, measured by determining the maximum slope of the MET current-deflection relationship, was lower than that in controls for both IHCs and OHCs $\left(\mathrm{P}<10^{-2}\right.$; Fig. 6, B and G). However, the adaptation characteristics of these MET currents in IHCs and OHCs (fast and slow adaptation time constants and extent of adaptation) displayed no significant alteration in the Myo3a ${ }^{-/-}$Myo3 $b^{-/-}$mice (Fig. 6, C-E and H-J).

We then explored the mechanosensitivity of the cochlear hair bundles containing supernumerary stereocilia in $\mathrm{Myo3a}^{-/-} \mathrm{Myo3}^{-/-}$mice, especially the abnormal circular bundles of the OHCs (Fig. 7). We developed a specific stimulator consisting of a fine vertical glass probe designed to fit inside such a circular bundle. In response to broad-amplitude, low-frequency sinusoidal stimulation $( \pm 1 \mu \mathrm{m}$ at $50 \mathrm{~Hz})$ applied with this probe, we recorded a periodic MET current displaying two positive-response phases per stimulation cycle (Fig. 7 A). This effect was likely caused by alternating "positive" and "negative" phases (directed toward and away from the kinocilium, 


\section{A Distribution of TRIOBP-containing rootlets in the hair bundle at P4}
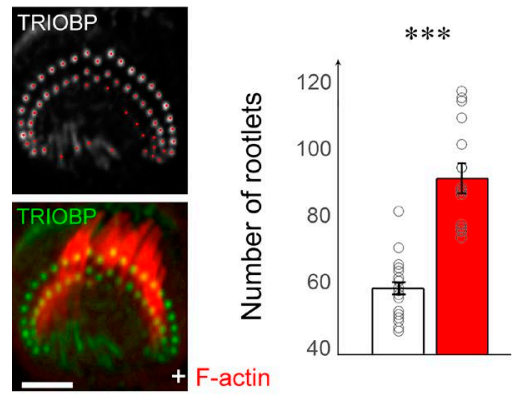

$\mathrm{IHC}$

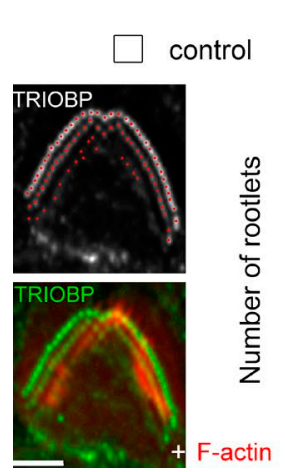

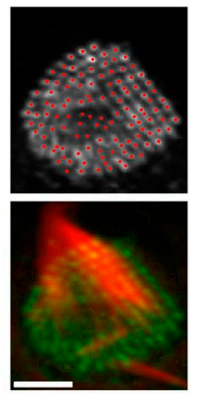

Муоза $\mathrm{a}^{-1-}$ Муо $3 b^{-/-}$

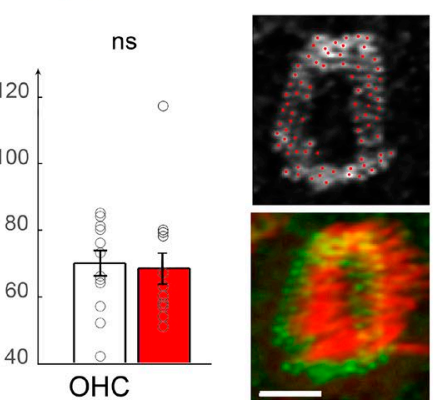

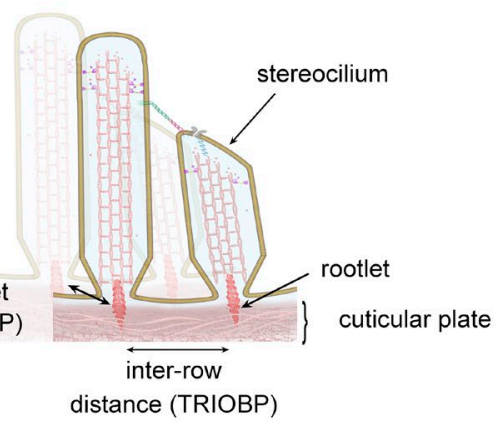

B Inter-row and intra-row spacing between rootlets in the hair bundle at P4 $(\mu \mathrm{m})$

\begin{tabular}{|c|c|c|c|}
\hline & & \multicolumn{2}{|c|}{ P4, mid-apex of the cochlea } \\
\hline & & control & Муо $3 a^{-1-}$ Муо $3 b^{-1-}$ \\
\hline \multirow{2}{*}{$\begin{array}{c}\text { intra-row rootlet } \\
\text { spacing (TRIOBP) }\end{array}$} & $\mathrm{IHC}$ & $0.43 \pm 0.04(n=21)$ & $0.37 \pm 0.04(n=15)$ \\
\hline & $\mathrm{OHC}$ & $0.29 \pm 0.03(n=13)$ & $0.36 \pm 0.05(n=11)$ \\
\hline \multirow{2}{*}{$\begin{array}{c}\text { inter-row } \\
\text { distance (TRIOBP) }\end{array}$} & $\mathrm{IHC}$ & $0.49 \pm 0.10(n=21)$ & $0.42 \pm 0.07(n=15)$ \\
\hline & $\mathrm{OHC}$ & $0.43 \pm 0.06(n=13)$ & $0.32 \pm 0.03(n=11)$ \\
\hline
\end{tabular}

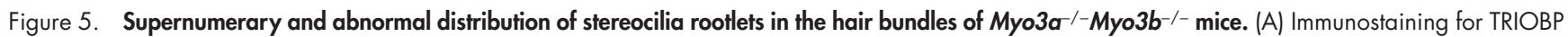

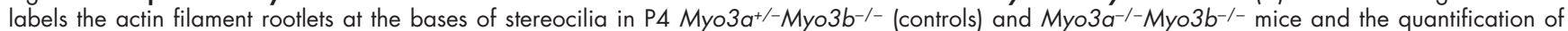
the number of stereocilia rootlets at the apical surfaces of the IHCs and OHCs. (B) Mean values (mean $\pm \mathrm{SEM}$ ) of interrow and intrarow spacing between rootlets. Bars, $2 \mu \mathrm{m}$. Asterisks indicate significance as in Table 1.

respectively) of hair bundle deflection. The rows of stereocilia with normal polarity were stimulated during the positive phase, evoking larger current responses, whereas those with the opposite polarity with respect to the kinocilium were stimulated during the negative phase, evoking smaller currents (Fig. 7 A, arrows). Both components of this current were blocked by the addition of $5 \mathrm{mM}$ BAPTA (Fig. 7 A, lower trace). This rules out a contribution to these currents of the "reversed polarity" MET reported in cochlear hair cells in the absence of tip links (Kim et al., 2013; Marcotti et al., 2014), which is calcium independent. When a step displacement of the probe was applied toward the medial side of the bundle (opposite to the kinocilium and corresponding to the inhibitory direction of MET in a wild-type hair bundle), small but consistent inward MET currents were recorded (averaging to $101 \pm 16 \mathrm{pA}, n=10 \mathrm{OHCs}$ ). These MET currents displayed fast activation and adaptation, with time constants similar to those measured in control hair cells (Fig. 7, B and C). They were inhibited by the application of $5 \mu \mathrm{M}$ FM1-43 (Fig. S3 B), which blocks hair cell MET channels (Gale et al., 2001).

These results establish that the Myo3a $a^{-/-} \mathrm{Myo3b}^{-/-}$hair bundles have MET currents with almost normal characteristics in terms of the response to deflections of their hair bundles. The morphologically mature supernumerary stereocilia that form in the defective $M y o 3 a^{-/-}$Myo $3 b^{-/-}$hair bundles also had almost normal MET current responses.

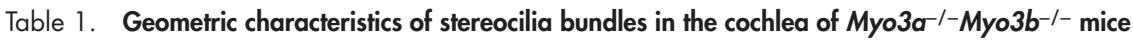

\begin{tabular}{|c|c|c|c|c|c|}
\hline \multirow[t]{2}{*}{ Characteristic } & \multirow[t]{2}{*}{ Hair cell } & \multicolumn{2}{|c|}{ P0, apex of the cochlea } & \multicolumn{2}{|c|}{ P9, apex of the cochlea } \\
\hline & & Control & Myo3a-/-Myo3b-/- & Control & Myo3a-/-Myo3b-/- \\
\hline \multirow[t]{2}{*}{ Projected height } & $\mathrm{IHC}$ & $1.04 \pm 0.28(n=17)$ & $2.04 \pm 0.50(n=13)^{* \star \star}$ & $1.45 \pm 0.38(n=6)$ & $2.33 \pm 0.57(n=12)^{* *}$ \\
\hline & $\mathrm{OHC}$ & $0.74 \pm 0.36(n=31)$ & $0.94 \pm 0.31(n=83)^{\star \star}$ & $0.47 \pm 0.17(n=22)$ & $0.95 \pm 0.24(n=39)^{\star \star *}$ \\
\hline \multirow[t]{2}{*}{ Number of stereocilia } & $\mathrm{IHC}$ & $25.4 \pm 5.4(n=17)$ & $39.9 \pm 5.3(n=13)^{\star \star \star}$ & $18.3 \pm 4.95(n=6)$ & $25.5 \pm 7.3(n=12)^{\star}$ \\
\hline & $\mathrm{OHC}$ & $31.1 \pm 4.3(n=31)$ & $42.7 \pm 9.2(n=95)^{\star \star \star}$ & $30.1 \pm 3.1(n=34)$ & $28.3 \pm 9.96(n=55)^{\mathrm{ns}}$ \\
\hline \multirow[t]{2}{*}{ Interstereocilia distance } & $\mathrm{IHC}$ & $0.33 \pm 0.09(n=17)$ & $0.20 \pm 0.04(n=13)^{* * *}$ & $0.41 \pm 0.10(n=6)$ & $0.48 \pm 0.15(n=12)^{\mathrm{ns}}$ \\
\hline & $\mathrm{OHC}$ & $0.18 \pm 0.02(n=31)$ & $0.18 \pm 0.07(n=95)^{\mathrm{ns}}$ & $0.29 \pm 0.04(n=34)$ & $0.32 \pm 0.09(n=55)^{\mathrm{ns}}$ \\
\hline \multirow[t]{2}{*}{ Interrow distance } & $\mathrm{IHC}$ & $0.39 \pm 0.09(n=17)$ & $0.24 \pm 0.04(n=13)^{\star \star \star \star}$ & $0.56 \pm 0.21(n=6)$ & $0.53 \pm 0.10(n=12)^{\mathrm{ns}}$ \\
\hline & $\mathrm{OHC}$ & $0.17 \pm 0.03(n=29)$ & $0.21 \pm 0.05(n=83)^{* \star * *}$ & $0.35 \pm 0.07(n=50)$ & $0.32 \pm 0.07(n=57)^{*}$ \\
\hline \multirow[t]{2}{*}{ Number of "side" rows } & $\mathrm{IHC}$ & $0.0 \pm 0.0(n=17)$ & $1.62 \pm 0.87(n=13)^{* \star *}$ & $0.0 \pm 0.0(n=6)$ & $0.92 \pm 0.51(n=12)^{* * \star}$ \\
\hline & $\mathrm{OHC}$ & $0.0 \pm 0.0(n=31)$ & $1.20 \pm 0.85(n=95)^{\star \star \star}$ & $0.0 \pm 0.0(n=28)$ & $0.89 \pm 0.88(n=55)^{\star \star \star *}$ \\
\hline
\end{tabular}

Geometric parameters of hair bundles (mean \pm SD). All distances are in micrometers. The interrow distance is defined as the mean distance between the three rows of stereocilia.

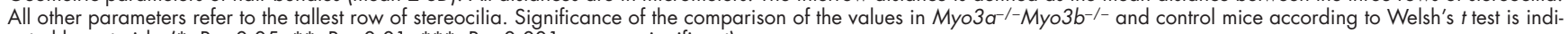
cated by asterisks (*, P<0.05; **, P<0.01; ***, P<0.001; ns, non-significant). 
A MET currents in P7 IHCs

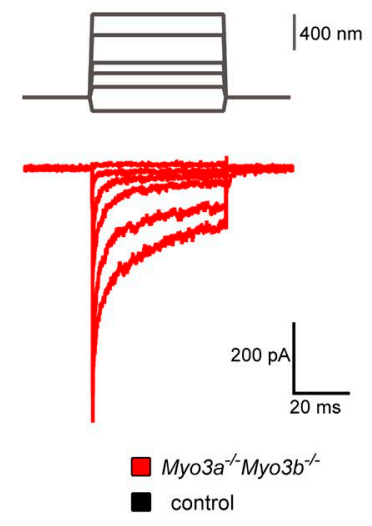

F MET currents in P7 OHCs
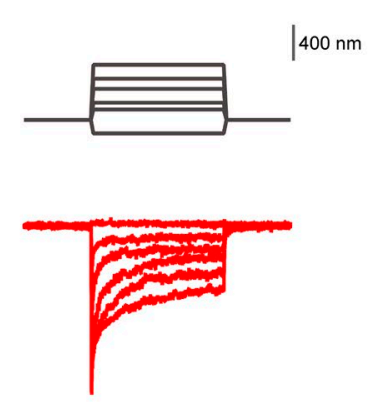

$200 \mathrm{pA}\rfloor \frac{}{20 \mathrm{~ms}}$
B $\quad \mathrm{I}(\mathrm{X})$ relationship

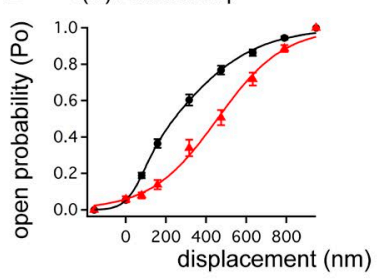

D Fast adaptation rate
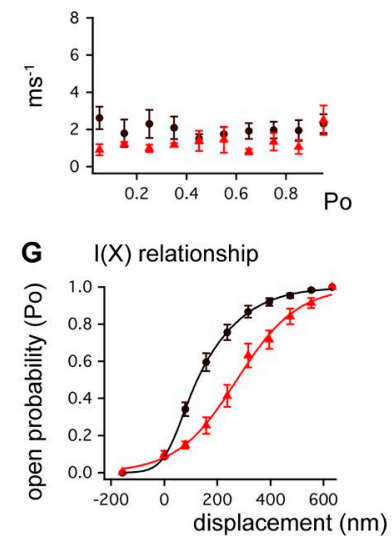

I Fast adaptation rate

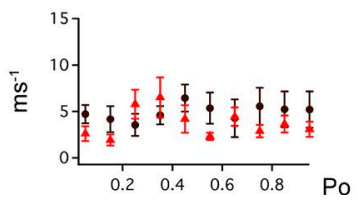

C Extent of adaptation

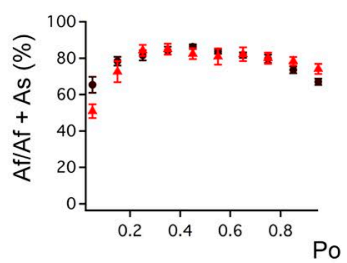

E Slow adaptation rate

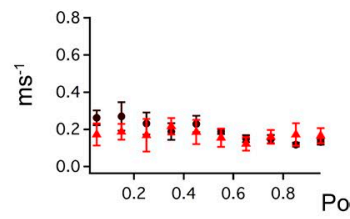

H Extent of adaptation

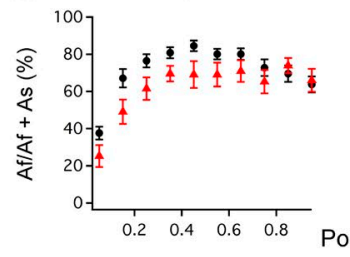

J Slow adaptation rate

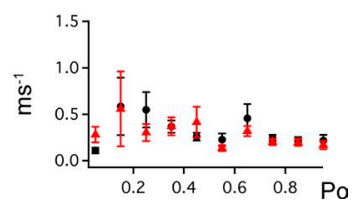

Figure 6. Cochlear hair cells of P7 Myo3a- $a^{-/-}$Myo3b-/- mice display normal MET features. (A and F) The mechanical stimulation protocol (upper traces), with examples of MET

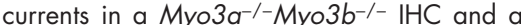
Myo3a-/-Myo3b-/- OHC (red traces). (B and G) The mean amplitude-displacement relationships $[I(X)]$ in both IHCs $(n=6)$ and $\mathrm{OHCs}$ $(n=11)$ from Myo3a-1-Myo3b-/- mice show a reduced response sensitivity compared with IHCs $(n=25)$ and OHCs $(n=19)$ from control mice (wild-type or $\mathrm{Myo} \mathrm{a}^{+/-} \mathrm{Myo} 3 \mathrm{~b}^{-/-}$littermates). ( $\mathrm{C}-\mathrm{E}$ and $\mathrm{H}-\mathrm{J}$ ) Adaptation characteristics of MET currents lextent, $\mathrm{C}$ and $\mathrm{H}$; fast rate, $\mathrm{D}$ and I; slow rate, $\mathrm{E}$ and $\mathrm{J}$ ) in either $\mathrm{IHCs}$ or OHCs from Myo3a-/-Myo3b-/- mice do not differ significantly from those measured in control $\mathrm{IHCs}$ or OHCs.
The myosin IIla binding partners espin-1 and MORN4 are targeted to the tips of cochlear stereocilia in Myo3a $a^{-/}$Myo3 $b^{-/}$mice

Espins, a class of actin-bundling proteins critical for the formation of stereocilia and other actin-filled protrusions (Loomis et al., 2003), include espin-1, which has been proposed to be targeted to the stereocilia tips by myosin IIIa (Salles et al., 2009). We thus investigated whether this protein is present in the cochlear hair bundles of $\mathrm{Myo} \mathrm{a}^{-/-} \mathrm{Myo} 3 \mathrm{~b}^{-/-}$mice. We detected espin-1 in these bundles on $\mathrm{P} 0$, when it starts to be expressed in the rat cochlea (Sekerková et al., 2006; Fig. 8 A). It was located at the tips of the stereocilia in both IHCs and OHCs. Immunostaining experiments
A MET currents upon sinusioidal stimulation of a circular $\mathrm{OHC}$ hair bundle from a P7 $\mathrm{MyO}^{-1-} \mathrm{MyO} 3 \mathrm{~b}^{-/}$mouse

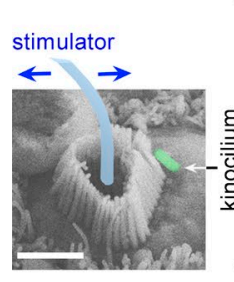

$100 \mathrm{pA}$
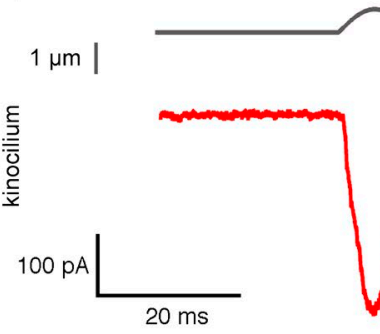

$20 \mathrm{~ms}$
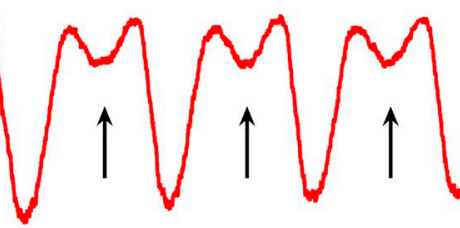

BAPTA 5 mM

B $\quad$ MET currents in a circular $\mathrm{OHC}$ hair bundle from a P7

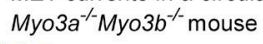

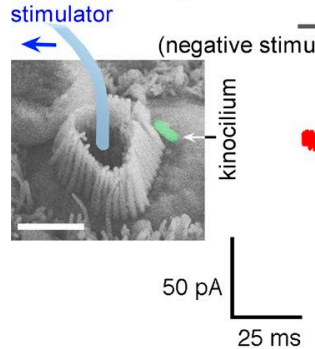

ulation)
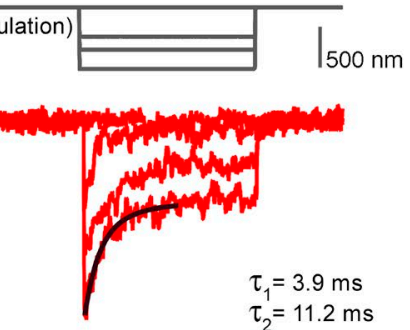

\section{C}

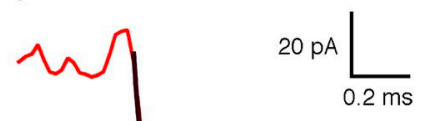

Figure 7. Supernumerary stereocilia in Myo3a ${ }^{-1-} \mathrm{Myo}^{3 b^{-/-}}$mice display inward MET currents. MET currents recorded from a P7 $\mathrm{OHC}$ with a circular hair bundle. The thin glass probe used to stimulate the bundle is illustrated in the insets (bar, $2 \mu \mathrm{m})$. (A) Response to a sine wave deflection (protocol shown in the upper gray trace). The phase of stimulation directed toward the kinocilium, and that directed in the opposite (negative) direction, both elicit depolarizing inward MET currents (the latter of smaller amplitude, arrows) that are sensitive to treatment with $5 \mathrm{mM}$ BAPTA (lower trace). (B) Response to displacement steps in the negative direction (protocol shown above). The fast and slow adaptation time constants indicated were estimated by fitting a double exponential $y=y_{0}+A_{1} \exp \left(-\Delta x / \tau_{1}\right)+A_{2} \exp \left(-\Delta x / \tau_{2}\right)$ to the maximum displacement response (black curve; fit parameters: $y_{0}=-36.1 \mathrm{pA}, A_{1}=$ $\left.-27.8 \mathrm{pA}, A_{2}=-13.5 \mathrm{pA} ; x_{0}=50.6 \mathrm{~ms}\right)$. (C) The activation time constants of the MET current traces shown in $B$, estimated from a single exponential fit, are similar to those of MET currents recorded in control OHCs. 

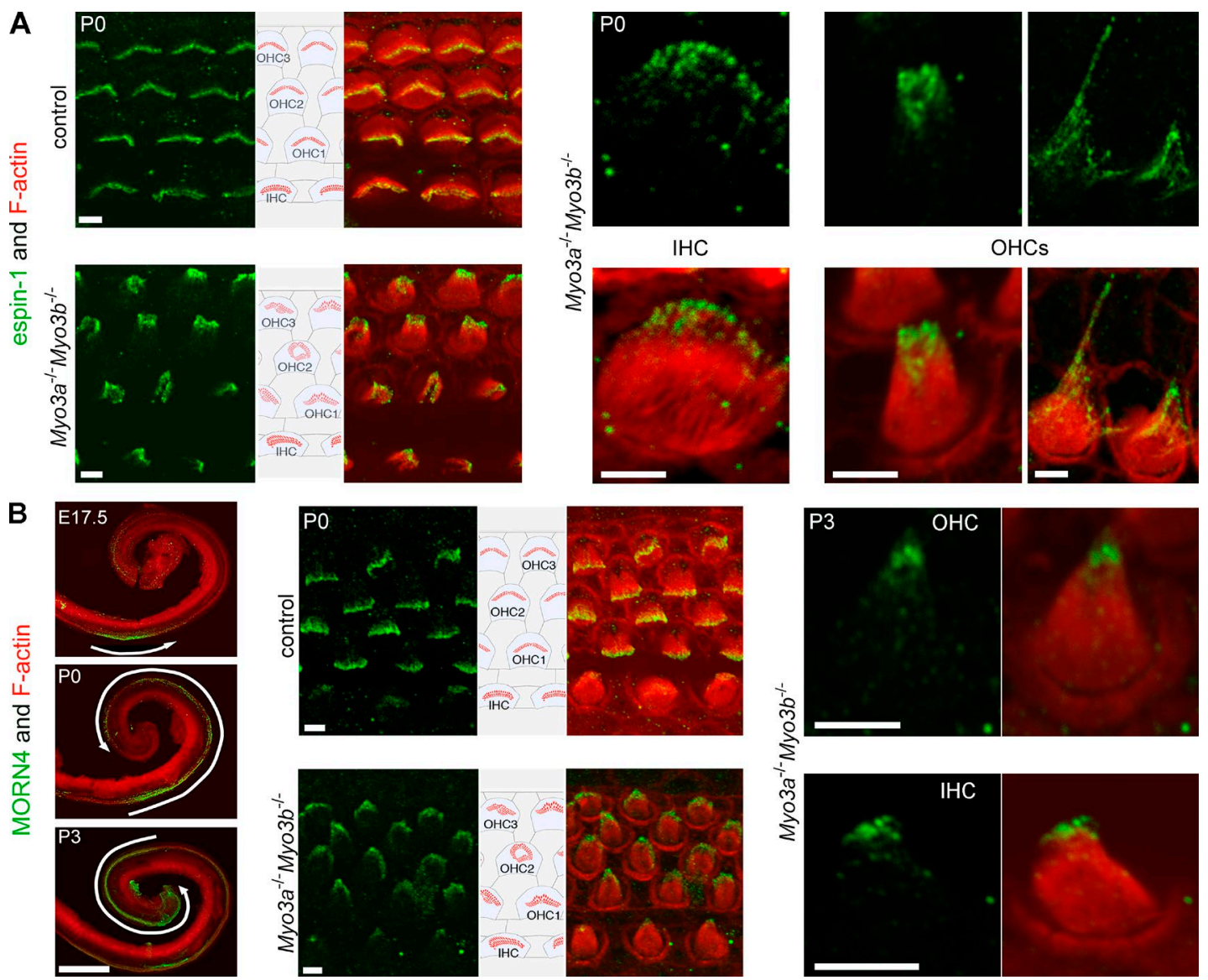

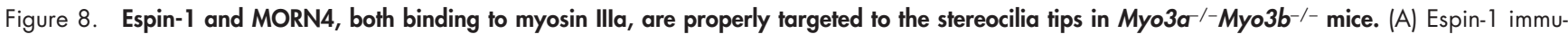

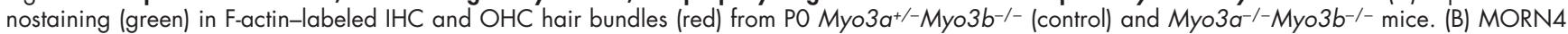

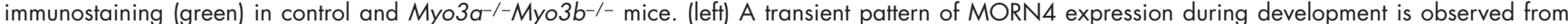
the base to the apex of the cochlea between E17.5 and P3. (middle and right) MORN4 is detected at the stereocilia tips in IHC and OHC hair bundles in

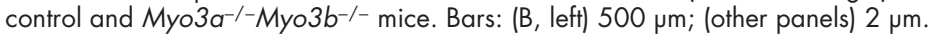

using pan-espin antibodies, detecting all espin isoforms, showed their presence over the length of the stereocilia shafts, both in $M y o 3 a^{-/-} \mathrm{Myo} 3 b^{-/-}$and in control mice (Fig. S4 A). The immunostaining of espin-1 and other espin isoforms included stereocilia of the normal-looking hair bundles, those forming abnormal side rows, those of long amorphous bundles, and central microvilli displaying exuberant growth in OHCs. Thus, unexpectedly, the absence of myosins IIIa and IIIb does not impair the concentration of espin-1 at the tips of cochlear stereocilia.

We wondered whether this conclusion could be extended to other binding partners of class III myosins. Using the yeast two-hybrid system (Fig. S5 A), we identified several potential partners of this myosin. We focused on retinophilin/MORN4, a protein with four membrane occupation and recognition nexus (MORN) repeats, given its role in the membrane association and stabilization of protein complexes (Ma et al., 2006) and the reported in vitro interaction between MORN4 and myosin IIIa (Mecklenburg et al., 2015). We confirmed this interaction by coimmunoprecipitation assays and colocalization experiments in transfected HEK293 cells (Fig. S5, B and C). A basal-to-apical wave of MORN4 expression progressed along the length of the cochlea from E17.5 to P6 (Fig. $8 \mathrm{~B}$, left). MORN4 was present at the tips of the stereocilia in both IHCs and $\mathrm{OHCs}$, indicating a colocalization with myosin IIIa. In $\mathrm{Myo3a}^{-/-} \mathrm{Myo} 3 b^{-/-}$cochlear hair cells, the MORN4 staining remained at the stereocilia tips, although it was fainter and less uniform than in control hair cells (Fig. 8 B, middle and right). We extended our analysis to two additional potential binding partners of myosin IIIa in cochlear hair bundles: coronin-1a (found with the PPI Finder tool; He et al., 2009), an actin-binding protein that promotes the cofilinmediated severing of actin filaments (Jansen et al., 2015), and espin-like, an espin paralogue similar in structure to espin-1 (Shin et al., 2013; Zheng et al., 2014). Both coronin-1 and espin-like had similar locations at the tips of cochlear stereocilia in the presence and in the absence of class III myosins (Fig. S4, D and E).

\section{Discussion}

These morphological and functional analyses of mice lacking one or both class III myosins demonstrate the key implication of these myosins in the early steps of cochlear hair bundle morphogenesis (Fig. 9 A). Our results show that myosins IIIa and IIIb play critical redundant roles during that period but are dispensable for the acquisition of several characteristics of mature hair bundles. Our main conclusion is that these myosins limit the growth of microvilli within the forming auditory hair bundles and thereby contribute to the architecture of the hair bundle, including its staircase pattern. Unexpectedly, the stereocilia of $\mathrm{Myo3a}^{-/-} \mathrm{Myo} \mathrm{b}^{-/-}$cochlear hair bundles are abnormally tall 
A

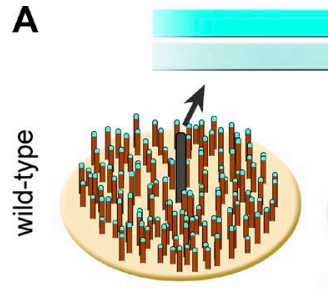

initial selection \& formation of a staircase myosin IIla expression myosin IIIb expression

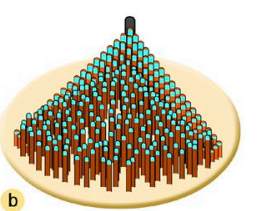

\&

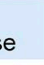

stabilization of ' $V$ '-shape

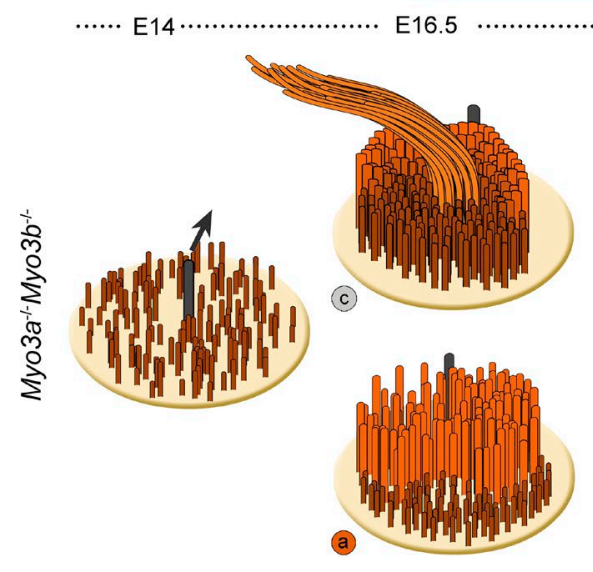

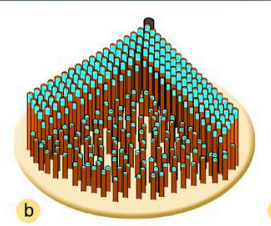

second phase of stereocilia growth \& regression of microvilli
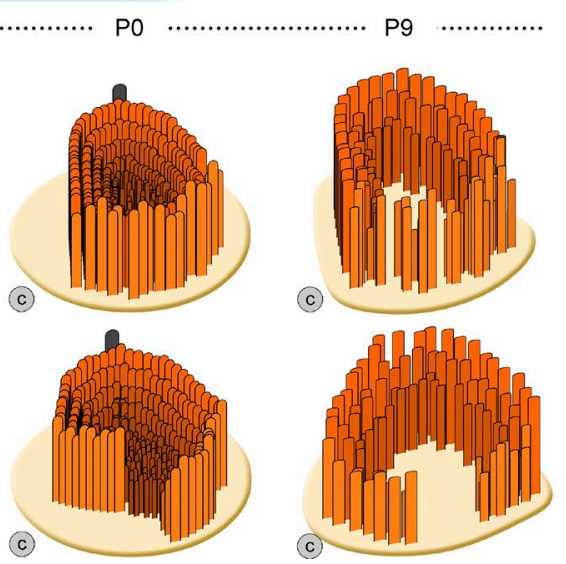

B
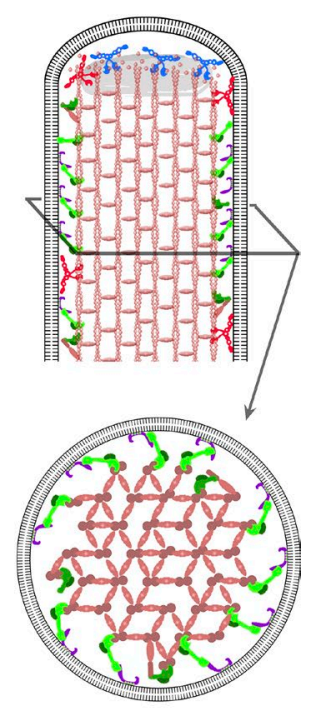

myosin IIla
myosin IIlb
espin-1
MORN4
myosin VIla
myosin XVa

Figure 9. Schematic representations illustrating the role of class III myosins in the developing cochlear hair bundles. (A) OHC hair bundle formation in wildtype and $\mathrm{Myo} \mathrm{a}^{-/-} \mathrm{Myo} 3 \mathrm{~b}^{-/-}$mice. On E14, undifferentiated microvilli cover the apical surface of the differentiating hair cell. E14-E16.5 period: the first phase of stereocilia growth after the kinocilium migration; in $\mathrm{Myo3}^{-/-} \mathrm{Myo} 3 \mathrm{~b}^{-/-}$mice, unstable growth of stereocilia perturbs their initial organization and selection, resulting in "long amorphous" bundles (a) and other shape abnormalities including exuberant F-actin protrusions (c). E16.5-PO period: stabilization of the $\mathrm{V}$ shape; in $\mathrm{Myo} 3 \mathrm{a}^{-/-} \mathrm{Myo} 3 \mathrm{~b}^{-/-}$mice, hair bundles stabilize but remain affected by various shape abnormalities. PO-P9 period: second phase of stereocilia growth. Past this stage, only myosin Illa is expressed in wild-type hair cells. (B) Suggested action of myosins Illa and IIlb in early hair bundle shaping; by forming a ring containing membrane-stabilizing proteins (e.g., MORN4), the two myosins regulate the membrane tension near stereocilia tips and/or the transport and function of proteins involved in the stereocilia actin turnover.

and display phenotypic features suggestive of an actin dynamic instability, indicating that class III myosins control the selective elongation of stereocilia by stabilizing their F-actin cores.

We measured robust MET currents in both IHCs and $\mathrm{OHCs}$ of $\mathrm{Myo3a}^{-/-} \mathrm{Myo3}^{-/-}$mice. The amplitude and sensitivity of these MET currents were smaller and more variable from cell to cell than those of control hair cells, but their kinetics and adaptation characteristics were normal, which appears to rule out an implication of these myosins in MET adaptation (Schneider et al., 2006). Incidentally, MET also occurred in the supernumerary stereocilia of circular OHC bundles, which display inward current responses when deflected in the direction opposite to the kinocilium. The MET currents of $\mathrm{Myo3a}^{-/-} \mathrm{Myo}^{-\mathrm{b}^{-/}}$ hair cells were consistent with an altered mechanical response of hair bundles due to their abnormal shapes, whereas the MET channels are otherwise properly functioning. Finally, the absence of an abnormal auditory phenotype in $M y o 3 a-c K O$ $M y o 3 b^{-/-}$mice, which lack both myosins IIIa and IIIb from P13, precludes a crucial role of these myosins in the maintenance of MET at mature stages.

We found that the constitutive absence of both class III myosins leads to profound deafness caused by hair bundle developmental defects. As neither $\mathrm{Myo3a}^{-/-}$mice nor $\mathrm{Myo} 3 \mathrm{~b}^{-/-}$ mice exhibit early hearing impairment, this demonstrates that myosins IIIa and IIIb are able to compensate for the loss of each other in the developing cochlea. A role for myosin IIIa in the maintenance of mature stereocilia has been suggested based on the implication of this protein in the DFNB30 late-onset form of deafness (Walsh et al., 2002), its localization at the tips of stereocilia (Schneider et al., 2006), and in vitro evidence of the elongation of stereocilia when myosin IIIa is overexpressed with espin-1 in hair cells at postnatal stages (Salles et al., 2009). Remarkably, the absence of hearing loss in Myo3a-cKO $M y o 3 b^{-/-}$mice pinpoints the compensatory mechanisms between myosins IIIa and IIIb as being critical during the period of hair bundle formation, but contrary to earlier suggestions, not at mature stages (Walsh et al., 2002; Schneider et al., 2006).

The hearing impairment of $M y o 3 a-c K O$ mice suggests that myosin IIIb exerts some deleterious effects on hearing past the developmental stages. In the absence of myosin IIIa, these deleterious effects would become apparent upon the abnormal compensatory recruitment of myosin IIIb in the hair bundle. It has indeed been shown that GFP-myosin IIIa can effectively outcompete mCherry-myosin IIIb because of its greater F-actin binding affinity and higher processive speed along actin filaments, enabling it to reach the tips of filopodia in COS-7 cells more rapidly (Manor et al., 2012; Merritt et al., 2012). Whatever the actual mechanisms involved, our findings suggest that the downregulation of $M Y O 3 B$ expression might be an effective way of preventing late-onset hearing loss in patients with $M Y O 3 A$ defects.

The normal positioning of the kinocilium and the almost normal orientation of $M y o 3 a^{-/-} \mathrm{Myo} \mathrm{b}^{-/-}$cochlear hair bundles on P0 argue against a role of these myosins in the establishment of hair bundle polarity. Consistently, Myo3a ${ }^{-/-} \mathrm{Myo}^{-/-}$ cochlear hair cells had a well-defined bare zone, to which the $\mathrm{G \alpha i}_{3}$ protein was restricted and from which Par- 6 was excluded 
(Fig. S2 B). However, these bundles failed to properly mold themselves into the V-shaped boundary of the bare zone.

After the kinocilium migration, the first phase of hair bundle growth starts. Lasting up to $\sim \mathrm{P} 0$, this phase normally marks the switch of microvilli-like protrusions to stereocilia, followed by the formation of an initial U- or V-shaped staircase of stereocilia (Fig. 9 A). The substantial fraction of abnormally shaped cochlear hair bundles in $M y o 3 a^{-/-} M_{y o 3} b^{-/-}$mice on E16.5 shows that the first phase of hair bundle growth is defective in these mice. The exaggerated elongation and number of microvilli and stereocilia, together with the rapid changes in the distribution of hair bundle shape abnormalities in $\mathrm{Myo} \mathrm{a}^{-1-} \mathrm{Myo} \mathrm{b}^{-/-}$cochlear hair cells between E16.5 and P0, strongly suggest a perturbed control of F-actin turnover. The absence of hair bundle defects in $\mathrm{Myo} \mathrm{a}^{-/-}$and $\mathrm{Myo3} \mathrm{b}^{-/-}$mice point at properties common to myosins IIIa and IIIb, which ensure the correct unfolding of this first step of hair bundle formation in the single mutants. Together, our results imply that these myosins operate during the early and most dynamic phase of hair bundle growth, during which microvilli are driven to differentiate into growing stereocilia or to regress. It is tempting to hypothesize that class III myosins contribute to the transition from a highly dynamic mode of stereocilia growth, which might involve an actin treadmill as suggested earlier (Rzadzinska et al., 2004), to a mode that seems not to depend on actin treadmill and is much more stable (Zhang et al., 2012; Narayanan et al., 2015; Drummond et al., 2015), at least in mice (Hwang et al., 2015).

The second phase of cochlear bundle growth, from P0 up to hearing onset (P12), leads to the widening and further elongation or shortening of the three tallest rows of stereocilia and the regression of the other rows and additional microvilli (Fig. 9). In both IHCs and OHCs of $\mathrm{Myo3a}^{-/-} \mathrm{Myozb}^{-/-}$mice, an overelongation of the stereocilia persists between $\mathrm{P} 0$ and $\mathrm{P} 9$, and a widening of the stereocilia accompanies their increased spacing (Fig. 3 B). In addition, Myo3 $a^{-1-} \mathrm{Myo}^{-1-}$ stereocilia develop rootlets and contain the major proteins involved in hair bundle maturation, including the USH proteins (Fig. S4, B and C). Together, our data do not provide support for an alteration of the maturation of cochlear hair bundles in the absence of class III myosins. It remains to be determined to which extent the lack of activity of these myosins contributes to the worsening of the shape abnormalities affecting $\mathrm{Myo3}^{-/-} \mathrm{Myo} \mathrm{b}^{-/-}$cochlear hair bundles in the second phase of stereocilia growth.

The ex vivo observation that class III myosins can promote the elongation of F-actin protrusions by transporting espin-1 to their tips (Salles et al., 2009; Merritt et al., 2012) suggested that the loss of these myosins should lead to abnormally short hair bundles. We observed instead a marked elongation of microvilli or stereocilia in the cochlear hair bundles of Myo3a $a^{-/}$Myo3b $b^{-/}$mice. The normal immunostaining pattern of espin-1 in these hair bundles establishes that myosins IIIa and IIIb are dispensable for the targeting of this espin isoform to the tips of stereocilia in vivo. Notably, class III myosins are also dispensable for the targeting of some of their other interacting or potentially interacting proteins, including MORN4, espin-like, and coronin-1a. Also consistent with the proper targeting of espin-1 in the absence of myosins IIIa and IIIb, a cochlear phenotype opposite to that of $\mathrm{Myo} \mathrm{a}^{-/-} \mathrm{Myo}^{3 \mathrm{~b}^{-/-}}$mice is observed in the Jerker (je/je) mice that carry a mutation inactivating the gene coding for all espin isoforms (Sekerková et al., 2004). Jerker mice have abnormally thin and short stereocilia from P0 onwards in both IHCs and OHCs, but the formation of the initial $\mathrm{U}$ or $\mathrm{V}$ bundle shapes and the first phase of stereocilia elongation appear unaffected (Sekerková et al., 2011). This suggests that the early role of class III myosins in hair bundle morphogenesis is in fact independent of espins. However, we noted occasional, intriguing similarities between the hair bundle defects of heterozygous Jerker $(j e /+)$ mice and those of myosin III mutant mice. These include a base-to-tip tapering of je/+ IHC stereocilia on P5, similar to the tapering observed in

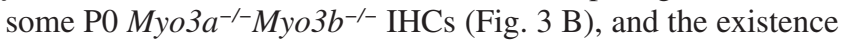
of transient thin outgrowths at the very tips of stereocilia in a few Myo3a $a^{+/-}$Myo3b $^{-/-}$IHCs on P0 (Fig. S3 C), similar to the transient "candlewick-like" tapering reported in the vestibular stereocilia of jel+ mice (Sekerková et al., 2011). Thus, subtle functional interactions between class III myosins and espin-1 might take place in the early developing cochlear hair bundles.

The fate of F-actin-filled protrusions is determined by the balance between the outward-pushing force of the growing F-actin bundle and the membrane tension forces that oppose this growth (Prost et al., 2007; Orly et al., 2014). The protrusion grows, regresses, or remains stable according to whether the balance is positive, negative, or at equilibrium. By acting on this balance, the activity of class III myosins could control the selection of the microvilli to become stereocilia. Any perturbation of this activity would thus have profound effects on hair bundle shape. The ringlike distribution of these myosins (Schneider et al., 2006), enclosing the stereocilia actin cores just below $(\sim 0.2 \mu \mathrm{m})$ the tips while being excluded from the tips (Fig. 1, E and F), is highly suggestive of their association with the membrane of stereocilia. Myosin IIIa, presumably coupled to the membrane by stabilizing proteins such as MORN4 (Fig. 9 B), may help to dynamically reinforce the membrane tension near the tips of stereocilia. Such a myosin III-driven dynamic ring, we suggest, would be ideally positioned for a finely tuned control of the membrane tension at the tips of stereocilia during their most dynamic period of growth. In addition, considering the regulatory roles conferred to class III myosins by their N-terminal kinase domain (Dosé et al., 2008), such a ring could act as a "funnel controller," downregulating the function or limiting the supply of actin-binding or actin-regulatory proteins to the barbed ends of actin filaments in developing stereocilia. Our findings reveal a previously unsuspected critical role of class III myosins in the control of the selective growth of stereocilia during the early phase of cochlear hair bundle formation.

\section{Materials and methods}

\section{Generation of single- and double-knockout mice for myosin Illa and myosin IIIb}

We first generated $\mathrm{Myo3}^{-/-}$and $\mathrm{Myo} \mathrm{b}^{-/-}$mouse strains displaying an early constitutive deletion of the gene encoding myosin IIIa and the gene encoding myosin IIIb, respectively. We generated $M y o 3 a^{\mathrm{f} / \mathrm{fl}}$ mice by floxing exons 4 and 5 of Myo3a. These mice were crossed with $P G K$-cre mice expressing the cre recombinase gene (cre) under the control of the early and ubiquitously active phosphoglycerate kinase-1 (PGK) gene promoter (Lallemand et al., 1998) to obtain $\mathrm{Myo3a}^{-/-}$ mice. The $M y o 3 b^{-1-}$ mouse strain was generated by a simpler strategy, in which exons 3 and 4 of the Myo3b gene were disrupted by a lacZ/ Neo cassette insertion (Texas A\&M Institute for Genomic Medicine). Myo3 $a^{-1-} \mathrm{Myo}^{-1-} \mathrm{b}^{-/}$mice were obtained by first crossing the $M y o 3 b^{-/-}$ strain with $\mathrm{Myo} \mathrm{a}^{+/-}$heterozygous mice, as this approach was more successful than direct crosses with $\mathrm{Myo3a}^{-/-}$mice. Myo3a $\mathrm{a}^{+/-} \mathrm{Myo} 3 \mathrm{~b}^{-/-}$ pups were selected and crossed. The resulting mice reproduced as effi- 
ciently as wild-type mice, and their genotypes $\left(\mathrm{Myo3a}^{-/} \mathrm{Myo}^{-/-}\right.$and $M y o 3 a^{+/-}$Yyo3 $^{-/-}$) followed a 1:1 ratio, consistent with Mendelian segregation rules. Mice with a postnatal conditional deletion of Myo3a were produced by crossing Myo3 $a^{f / A}$ mice with Myo15-cre recombinant mice expressing cre under the control of the Myo15 promoter. In the resulting Myo3a-cKO mice, Myo3a is inactivated from P1 onwards at the base of the cochlea and throughout the cochlea a few days later (Caberlotto et al., 2011). Similarly, we generated Myo3a-cKO Myo3b ${ }^{-1-}$ mice carrying both the same postnatal inactivation of Myo3a from P1 onward and a constitutive deletion of $M y o 3 b$, by first crossing $M y o 3 a^{\mathrm{t} / \mathrm{fl}}$ and $M y o 3 b^{-/-}$ mice together and then crossing the offspring of this cross with Myo15cre mice. The morphological and physiological data did not differ among heterozygous ( $\mathrm{Myo3a}^{+-}, \mathrm{Myo3b}^{+-}$, or $\mathrm{Myo3a}^{+/-} \mathrm{Myo}^{-b^{--}}$), floxed ( $M y o 3 a^{\mathrm{f} / \mathrm{fl}}$ or $M y o 3 a^{\mathrm{f} / \mathrm{fl}} \mathrm{Myoz}^{-/-}$) mutant mice, and wild-type mice; they were thus used indifferently as controls in our analyses.

\section{Audiometric recordings}

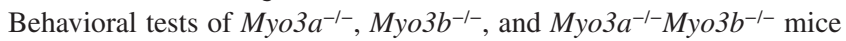
revealed no apparent vestibular defect, so we focused on their hearing abilities. ABRs and DPOAEs were recorded as previously described (Le Calvez et al., 1998). ABR waves were recorded in response to pure tone bursts at frequencies of $10,15,20$, and $32 \mathrm{kHz}$ in mice aged between 1 and 6 mo. ABR thresholds were determined as the lowest stimulus for which recognizable ABR waves were observed. DPOAEs were collected with a miniature microphone positioned at the entry of the ear canal. Two primary pure-tone stimuli of frequencies $f_{1}$ and $f_{2}$ were applied simultaneously, where $f_{2}$ was between 5 and $20 \mathrm{kHz}$ and the $f_{2} / f_{1}$ ratio was kept constant at 1.2 . The cubic difference tone at $2 f_{1}-f_{2}$, the most prominent distortion product tone produced by mammalian ears, was measured for primary tones having equal levels, ranging from 30 to $75 \mathrm{~dB}$ SPL. The data shown in Figs. 1 and S1 were obtained from recordings at the primary frequencies $f_{1}=15 \mathrm{kHz}$ and $f_{2}=18 \mathrm{kHz}$.

\section{MET current recordings}

All recordings were performed at cochlear positions lying 20\%-40\% from the cochlear apex of P7-P8 mice. Cochlear coils were finely dissected, placed under two nylon meshes, and observed under an Axioscope FS microscope (Carl Zeiss) fitted with a $40 \times$ water-immersion objective (Carl Zeiss). IHCs or OHCs were subjected to whole-cell voltage clamping at $-80 \mathrm{mV}$ and $20^{\circ} \mathrm{C}-25^{\circ} \mathrm{C}$, with an EPC-10 patch-clamp amplifier (HEKA). The extracellular solution contained $146 \mathrm{mM} \mathrm{NaCl}, 5.8 \mathrm{mM}$ $\mathrm{KCl}, 1.5 \mathrm{mM} \mathrm{CaCl}_{2}, 0.7 \mathrm{mM} \mathrm{NaH}_{2} \mathrm{PO}_{4}, 2 \mathrm{mM}$ sodium pyruvate, $10 \mathrm{mM}$ glucose, and $10 \mathrm{mM}$ Hepes, pH 7.4 (305 mosmol $/ \mathrm{kg})$. Borosilicate patch pipettes (1-2 M $\Omega$ ) were backfilled with an intracellular solution containing $130 \mathrm{mM} \mathrm{KCl}, 10 \mathrm{mM} \mathrm{NaCl}, 3.5 \mathrm{mM} \mathrm{MgCl} 2,1 \mathrm{mM}$ EGTA, $5 \mathrm{mM}$ potassium ATP, $0.5 \mathrm{mM} \mathrm{GTP}$, and $5 \mathrm{mM}$ Hepes, $\mathrm{pH} 7.4$ (290 mosmol/kg). No correction was made for liquid junction potential. Series resistance was always $<10 \mathrm{M} \Omega$ and was compensated to $70 \%$. Hair bundles were mechanically stimulated with a rigid glass rod that had been fire-polished to fit the normal hair bundles. A specific stimulator was also designed to fit the abnormal circular OHC hair bundles in $\mathrm{Myo} \mathrm{a}^{-1-} \mathrm{Myo} 3 \mathrm{~b}^{-/-}$mice. The probe was attached to a piezoelectric actuator (PA8/12; Piezosystem Jena) driven by a fast voltage amplifier (ENV800; Piezosystem Jena). The resonance of the actuator was decreased by subjecting the stimulating signal of the EPC-10 amplifier to low band-pass filtering at $5 \mathrm{kHz}$ with a Bessel four-pole filter (model 3362; Krohn-Kite). MET current responses were typically averaged over five consecutive stimulations.

\section{Antibodies and immunostaining of whole-mount cochleas}

We generated polyclonal antibodies against myosin IIIa, myosin IIIb, and espin-1 by injecting specific peptides into rabbits. For myosin IIIa, we used the amino acid sequence reported in a previous study (Schnei- der et al., 2006). For myosin IIIb, we used the sequence SPEDTMYY NQLNGTLEYQGSQRKPRKLGQIKVLDGEDQYYKCLSPGACAPE ETHSVHPFFFSSSPREDPFAQH (Agro-Bio), and for espin-1, we used the sequence LDALPVHHAARSGKLHCLR (Proteogenix; Salles et al., 2009). We checked that our anti-myosin IIIa and anti-myosin IIIb antibodies were specific by immunofluorescence experiments in which $\mathrm{Myo3}^{-/-}$and $\mathrm{Myo}^{-1-} \mathrm{b}^{-/}$mice were used as negative controls (Fig. S1, $\mathrm{A}$ and B). Rabbit polyclonal antibodies raised earlier in the laboratory were also used: antibody H1b against harmonin- $\beta$ (Boëda et al., 2002), antibody P1CD1-3 against all isoforms of protocadherin-15 (Sahly et al., 2012; Pepermans et al., 2014), and antibodies against the N-terminal region of the murine VLGR1 protein (Michalski et al., 2007). In addition, commercially available antibodies were used against the following proteins: Par-6b, myosin VIIa, pan-espin (Santa Cruz Biotechnology); $\mathrm{G}_{3} \mathrm{i}_{3}$ (Sigma-Aldrich); MORN4 (Sigma-Aldrich and Abcam); TRIOBP (Sigma-Aldrich); and espin-like and coronin-1A (Abcam). All these antibodies are raised in rabbits and are polyclonal, except the anti-myosin VIIa antibodies, which are raised in mice and are monoclonal.

For immunofluorescence analysis, cochlear explants were dissected and fixed in either $1 \%$ PFA at $4{ }^{\circ} \mathrm{C}$ overnight (embryonic and $\mathrm{P} 0$ cochleas) or $2 \% \mathrm{PFA}$ at room temperature for $30 \mathrm{~min}$ (later stages). Samples were processed as previously described (Sahly et al., 2012). They were then immersed in a permeabilizing solution (20\% normal goat serum and $0.5 \%$ Triton $\mathrm{X}-100$ ) for $1 \mathrm{~h}$ and exposed to primary antibodies at $4{ }^{\circ} \mathrm{C}$ overnight. For anti-MORN4 and anti-espin-like staining, an antigen retrieval method was used, consisting of immersion in citrate buffer ( $\mathrm{pH} 6$ ) heated at $60^{\circ} \mathrm{C}$ for $15 \mathrm{~min}$, between the permeabilization and blocking steps. Specific secondary antibodies were goat anti-rabbit Atto 488 or goat anti-mouse Atto 488 (Sigma-Aldrich). Atto 565 phalloidin (Sigma-Aldrich) was used to stain F-actin. Samples were imaged at room temperature with a confocal microscope (LSM 700; Carl Zeiss), with an oil-immersion Plan-Apochromat $\times 63$ NA 1.4 objective lens from Carl Zeiss.

\section{Coimmunoprecipitation experiments}

HEK 293T cells were transfected in the presence of Lipofectamine 2000 (Invitrogen). One of the following combinations of constructs were used for transfection: (1) a cDNA encoding the GFP-tagged myosin IIIa tail alone (aa 1,107-1,621; accession number NM_148413); (2) a cDNA encoding the GFP-tagged myosin IIIa tail with a cDNA encoding the Flag-tagged MORN4 fragment (aa 1-146; accession number NM_198108); or (3) a cDNA encoding the GFP-tagged myosin IIIa tail with a cDNA encoding the Flag-tagged spectrin $\beta$ II-R16 fragment, used as a negative control (C-terminal region of spectrin $\beta$ II starting from the spectrin repeat 16; aa 1,914-2,364; accession number NP_008877.1). Protein extracts were incubated at $4^{\circ} \mathrm{C}$ for $2 \mathrm{~h}$ with a mouse monoclonal antibody directed against FlagM2 (Sigma-Aldrich) and then for 30 min with protein G-coated $\mu$ MACS magnetic MicroBeads (Miltenyi Biotec). The bound proteins were denatured and eluted in $50 \mu 12 \times$ NuPAGE containing $1 \times$ SDS. Immunoprecipitates were run on 4\%-12\% NuPAGE gels (Invitrogen) and subjected to Western blot analysis. HRP-conjugated goat anti-rabbit or anti-mouse antibodies (Jackson ImmunoResearch Laboratories) and the ECL chemiluminescence system (Pierce) were used for detection of the proteins.

\section{Scanning electron microscopy and morphological analysis of cochlear hair bundles}

Samples were prepared for electron microscopy as previously described (Furness et al., 2008). In brief, cochleas were dissected, fixed in $2.5 \%$ glutaraldehyde in $0.1 \mathrm{mM}$ cacodylate buffer, and processed according to the osmium, thiohydrocarbazide impregnation method. 
Images were acquired with a JEOL JSM6700F electron microscope operating at $3 \mathrm{kV}$ (JEOL). Quantitative analysis of hair bundle geometry was performed on $\mathrm{P} 0$ for the base and apex of the cochlea and on P9 for the apex of the cochlea only. In all the images analyzed, the image plane coincided approximately with the surface of the epithelium in the $\mathrm{OHC}$ region, and the angle between the shafts of the stereocilia and the $z$ axis was $\sim 25^{\circ}$, with a variability of $\pm 10^{\circ}$, giving a projection factor of $\sim 0.4$ relative to actual stereocilium length. This uniformity of orientation made it possible to compare the relative heights of the stereocilia in each hair cell type between mutant and control mice. However, because of the orientation of the sample, typically only the lateral edge of the tallest row of stereocilia in the IHCs row was visible from base to tip, whereas a significant fraction of the tallest stereocilium shafts in the OHCs were generally visible. For this reason, projected stereocilium height measurements were more accurate for OHCs than for IHCs. A custom MATLAB (MathWorks) interface was used to select intensity profiles along the rows of stereocilia of each hair cell analyzed, facilitating the measurement of stereocilium numbers, projected heights, and the distances between stereocilia by the detection of profile maxima. Unless otherwise stated, all statistical comparisons were based on Welch's $t$ test.

\section{Online supplemental material}

Fig. S1 illustrates the validation of our antibodies against myosins IIIa and IIIb in $\mathrm{Myo3a}^{-/-}$and $\mathrm{Myo3}^{-/-}$mice, respectively, and shows physiological (DPOAE) results for these mice and for Myo3acKO $\mathrm{Myo} \mathrm{b}^{-1-}$ mice. Fig. S2 illustrates the absence of alteration of cochlear polarity cues in $M y o 3 a^{-1-} \mathrm{Myo} 3 b^{-1-}$ mice. Fig. S3 shows the interstereocilia links, the inhibition of MET currents by FM1-43 in a circular $\mathrm{Myo}^{-1-} \mathrm{Myo}^{-1} \mathrm{~b}^{-1-} \mathrm{OHC}$ bundle, and the occasional thinning of stereocilia tips in IHCs of $\mathrm{Myo3}^{+--} \mathrm{Myo} \mathrm{b}^{-/-}$heterozygous mice. Fig. S4 shows the distribution of espin isoforms, USH proteins, coronin-1a, and espin-like protein in cochlear hair bundles of $\mathrm{Myo3a}^{-1-} \mathrm{Myo} \mathrm{b}^{-1-}$ mice. Fig. S5 illustrates the in vitro interaction between myosin IIIa and MORN4. Online supplemental material is available at http://www.jcb.org/cgi/content/full/jcb.201509017/DC1.

\section{Acknowledgments}

We thank Jean-Pierre Hardelin for critical reading of the manuscript.

This research was funded by the European Research Council ladvanced grant "Hair bundle," ERC-201 1-AdG294570), the Agence Nationale de la Recherche (ANR; grant EARMEC, ANR-1 1BSV5-0011), ANR program "Investissements d'Avenir" (grant ANR10-LABX-65), Errera Hoechstetter, and the Foundation BNP Paribas.

The authors declare no competing financial interests.

Submitted: 2 September 2015

Accepted: 7 December 2015

\section{References}

Barr-Gillespie, P.-G. 2015. Assembly of hair bundles, an amazing problem for cell biology. Mol. Biol. Cell. 26:2727-2732. http://dx.doi.org/10.1091/ mbc.E14-04-0940

Beurg, M., R. Fettiplace, J.-H. Nam, and A.J. Ricci. 2009. Localization of inner hair cell mechanotransducer channels using high-speed calcium imaging. Nat. Neurosci. 12:553-558. http://dx.doi.org/10.1038/nn.2295

Boëda, B., A. El-Amraoui, A. Bahloul, R. Goodyear, L. Daviet, S. Blanchard, I. Perfettini, K.R. Fath, S. Shorte, J. Reiners, et al. 2002. Myosin VIIa, harmonin and cadherin 23 , three Usher I gene products that cooperate to shape the sensory hair cell bundle. EMBO J. 21:6689-6699. http://dx.doi .org/10.1093/emboj/cdf689
Caberlotto, E., V. Michel, I. Foucher, A. Bahloul, R.J. Goodyear, E. Pepermans, N. Michalski, I. Perfettini, O. Alegria-Prévot, S. Chardenoux, et al. 2011. Usher type $1 \mathrm{G}$ protein sans is a critical component of the tip-link complex, a structure controlling actin polymerization in stereocilia. Proc. Natl. Acad. Sci. USA. 108:5825-5830. http://dx.doi.org/10.1073/pnas .1017114108

Cotanche, D.A., and J.T. Corwin. 1991. Stereociliary bundles reorient during hair cell development and regeneration in the chick cochlea. Hear. Res. 52:379-402. http://dx.doi.org/10.1016/0378-5955(91)90027-7

Deans, M.R. 2013. A balance of form and function: planar polarity and development of the vestibular maculae. Semin. Cell Dev. Biol. 24:490498. http://dx.doi.org/10.1016/j.semcdb.2013.03.001

Delprat, B., V. Michel, R. Goodyear, Y. Yamasaki, N. Michalski, A. El-Amraoui, I. Perfettini, P. Legrain, G. Richardson, J.-P. Hardelin, and C. Petit. 2005. Myosin XVa and whirlin, two deafness gene products required for hair bundle growth, are located at the stereocilia tips and interact directly. Hum. Mol. Genet. 14:401-410. http://dx.doi.org/10.1093/hmg/ddi036

Denman-Johnson, K., and A. Forge. 1999. Establishment of hair bundle polarity and orientation in the developing vestibular system of the mouse. J. Neurocytol. 28:821-835. http://dx.doi.org/10.1023/A:1007061819934

Dosé, A., J. Lin-Jones, and B. Burnside. 2008. Class III myosins. In Myosins. L.M. Coluccio, editor. Springer, Dordrecht, Netherlands. 265-287.

Drummond, M.C., M. Barzik, J.E. Bird, D.-S. Zhang, C.P. Lechene, D.P. Corey, L.L. Cunningham, and T.B. Friedman. 2015. Live-cell imaging of actin dynamics reveals mechanisms of stereocilia length regulation in the inner ear. Nat. Commun. 6:6873. http://dx.doi.org/10.1038/ncomms7873

Ezan, J., L. Lasvaux, A. Gezer, A. Novakovic, H. May-Simera, E. Belotti, A.-C. Lhoumeau, L. Birnbaumer, S. Beer-Hammer, J.-P. Borg, et al. 2013. Primary cilium migration depends on G-protein signalling control of subapical cytoskeleton. Nat. Cell Biol. 15:1107-1115. http://dx.doi.org $/ 10.1038 / \mathrm{ncb} 2819$

Fettiplace, R., and K.X. Kim. 2014. The physiology of mechanoelectrical transduction channels in hearing. Physiol. Rev. 94:951-986. http://dx.doi .org/10.1152/physrev.00038.2013

Flock, A., and A.J. Duvall III. 1965. The ultrastructure of the kinocilium of the sensory cells in the inner ear and lateral line organs. J. Cell Biol. 25:18. http://dx.doi.org/10.1083/jcb.25.1.1

Furness, D.N., S. Mahendrasingam, M. Ohashi, R. Fettiplace, and C.M. Hackney. 2008. The dimensions and composition of stereociliary rootlets in mammalian cochlear hair cells: comparison between high- and lowfrequency cells and evidence for a connection to the lateral membrane. J. Neurosci. 28:6342-6353. http://dx.doi.org/10.1523/JNEUROSCI.1154 $-08.2008$

Gale, J.E., W. Marcotti, H.J. Kennedy, C.J. Kros, and G.P. Richardson. 2001. FM1-43 dye behaves as a permeant blocker of the hair-cell mechanotransducer channel. J. Neurosci. 21:7013-7025.

Gibson, F., J. Walsh, P. Mburu, A. Varela, K.A. Brown, M. Antonio, K.W. Beisel, K.P. Steel, and S.D. Brown. 1995. A type VII myosin encoded by the mouse deafness gene shaker-1. Nature. 374:62-64. http://dx.doi.org/10 $1038 / 374062 \mathrm{a} 0$

He, M., Y. Wang, and W. Li. 2009. PPI finder: a mining tool for human proteinprotein interactions. PLoS One. 4:e4554. http://dx.doi.org/10.1371/ journal.pone.0004554

Hwang, P., S.-W. Chou, Z. Chen, and B.M. McDermott Jr. 2015. The stereociliary paracrystal is a dynamic cytoskeletal scaffold in vivo. Cell Reports. 13:1287-1294. http://dx.doi.org/10.1016/j.celrep.2015.10.003

Jansen, S., A. Collins, S.M. Chin, C.A. Ydenberg, J. Gelles, and B.L. Goode. 2015. Single-molecule imaging of a three-component ordered actin disassembly mechanism. Nat. Commun. 6:7202. http://dx.doi.org/10 .1038/ncomms 8202

Jones, C., and P. Chen. 2008. Primary cilia in planar cell polarity regulation of the inner ear. Curr. Top. Dev. Biol. 85:197-224. http://dx.doi.org/10.1016 /S0070-2153(08)00808-9

Kaltenbach, J.A., P.R. Falzarano, and T.H. Simpson. 1994. Postnatal development of the hamster cochlea. II. Growth and differentiation of stereocilia bundles. J. Comp. Neurol. 350:187-198. http://dx.doi.org/10.1002/cne .903500204

Kim, K.X., M. Beurg, C.M. Hackney, D.N. Furness, S. Mahendrasingam, and R. Fettiplace. 2013. The role of transmembrane channel-like proteins in the operation of hair cell mechanotransducer channels. J. Gen. Physiol. 142:493-505. http://dx.doi.org/10.1085/jgp.201311068

Kitajiri, S., T. Sakamoto, I.A. Belyantseva, R.J. Goodyear, R. Stepanyan, I. Fujiwara, J.E. Bird, S. Riazuddin, S. Riazuddin, Z.M. Ahmed, et al. 2010. Actin-bundling protein TRIOBP forms resilient rootlets of hair cell stereocilia essential for hearing. Cell. 141:786-798. http://dx.doi.org/10 .1016/j.cell.2010.03.049 
Lallemand, Y., V. Luria, R. Haffner-Krausz, and P. Lonai. 1998. Maternally expressed PGK-Cre transgene as a tool for early and uniform activation of the Cre site-specific recombinase. Transgenic Res. 7:105-112. http:// dx.doi.org/10.1023/A:1008868325009

Le Calvez, S., P. Avan, L. Gilain, and R. Romand. 1998. CD1 hearing-impaired mice. I: Distortion product otoacoustic emission levels, cochlear function and morphology. Hear. Res. 120:37-50. http://dx.doi.org/10.1016/S0378 $-5955(98) 00050-1$

Lefèvre, G., V. Michel, D. Weil, L. Lepelletier, E. Bizard, U. Wolfrum, J.-P. Hardelin, and C. Petit. 2008. A core cochlear phenotype in USH1 mouse mutants implicates fibrous links of the hair bundle in its cohesion, orientation and differential growth. Development. 135:1427-1437. http:// dx.doi.org/10.1242/dev.012922

Lepelletier, L., J.B. de Monvel, J. Buisson, C. Desdouets, and C. Petit. 2013. Auditory hair cell centrioles undergo confined Brownian motion throughout the developmental migration of the kinocilium. Biophys. J. 105:48-58. http://dx.doi.org/10.1016/j.bpj.2013.05.009

Les Erickson, F., A.C. Corsa, A.C. Dose, and B. Burnside. 2003. Localization of a class III myosin to filopodia tips in transfected HeLa cells requires an actin-binding site in its tail domain. Mol. Biol. Cell. 14:4173-4180. http://dx.doi.org/10.1091/mbc.E02-10-0656

Loomis, P.A., L. Zheng, G. Sekerková, B. Changyaleket, E. Mugnaini, and J.R. Bartles. 2003. Espin cross-links cause the elongation of microvillustype parallel actin bundles in vivo. J. Cell Biol. 163:1045-1055. http://dx .doi.org/10.1083/jcb.200309093

Ma, H., Y. Lou, W.H. Lin, and H.W. Xue. 2006. MORN motifs in plant PIPKs are involved in the regulation of subcellular localization and phospholipid binding. Cell Res. 16:466-478. http://dx.doi.org/10.1038/sj.cr.7310058

Manor, U., A. Disanza, M. Grati, L. Andrade, H. Lin, P.P. Di Fiore, G. Scita, and B. Kachar. 2011. Regulation of stereocilia length by myosin XVa and whirlin depends on the actin-regulatory protein Eps8. Curr. Biol. 21:167-172. http://dx.doi.org/10.1016/j.cub.2010.12.046

Manor, U., M. Grati, C.M. Yengo, B. Kachar, and N.S. Gov. 2012. Competition and compensation: dissecting the biophysical and functional differences between the class 3 myosin paralogs, myosins $3 \mathrm{a}$ and $3 \mathrm{~b}$. BioArchitecture. 2:171-174. http://dx.doi.org/10.4161/bioa.21733

Marcotti, W., L.F. Corns, T. Desmonds, N.K. Kirkwood, G.P. Richardson, and C.J. Kros. 2014. Transduction without tip links in cochlear hair cells is mediated by ion channels with permeation properties distinct from those of the mechano-electrical transducer channel. J. Neurosci. 34:5505-5514. http://dx.doi.org/10.1523/JNEUROSCI.4086-13.2014

Mburu, P., X.Z. Liu, J. Walsh, D. Saw Jr., M.J. Cope, F. Gibson, J. KendrickJones, K.P. Steel, and S.D. Brown. 1997. Mutation analysis of the mouse myosin VIIA deafness gene. Genes Funct. 1:191-203. http://dx.doi.org /10.1046/j.1365-4624.1997.00020.x

Mecklenburg, K.L., S.A. Freed, M. Raval, O.A. Quintero, C.M. Yengo, and J.E. O'Tousa. 2015. Invertebrate and vertebrate class III myosins interact with MORN repeat-containing adaptor proteins. PLoS One. 10:e0122502. http://dx.doi.org/10.1371/journal.pone.0122502

Merritt, R.C., U. Manor, F.T. Salles, M. Grati, A.C. Dose, W.C. Unrath, O.A. Quintero, C.M. Yengo, and B. Kachar. 2012. Myosin IIIB uses an actin-binding motif in its espin-1 cargo to reach the tips of actin protrusions. Curr. Biol. 22:320-325. http://dx.doi.org/10.1016/j.cub.2011 .12 .053

Michalski, N., V. Michel, A. Bahloul, G. Lefèvre, J. Barral, H. Yagi, S. Chardenoux, D. Weil, P. Martin, J.-P. Hardelin, et al. 2007. Molecular characterization of the ankle-link complex in cochlear hair cells and its role in the hair bundle functioning. J. Neurosci. 27:6478-6488. http://dx .doi.org/10.1523/JNEUROSCI.0342-07.2007

Narayanan, P., P. Chatterton, A. Ikeda, S. Ikeda, D.P. Corey, J.M. Ervasti, and B.J. Perrin. 2015. Length regulation of mechanosensitive stereocilia depends on very slow actin dynamics and filament-severing proteins. Nat. Commun. 6:6855. http://dx.doi.org/10.1038/ncomms7855

Orly, G., M. Naoz, and N.S. Gov. 2014. Physical model for the geometry of actin-based cellular protrusions. Biophys. J. 107:576-587. http://dx.doi .org/10.1016/j.bpj.2014.05.040

Pepermans, E., V. Michel, R. Goodyear, C. Bonnet, S. Abdi, T. Dupont, S. Gherbi, M. Holder, M. Makrelouf, J.-P. Hardelin, et al. 2014. The CD2 isoform of protocadherin-15 is an essential component of the tip-link complex in mature auditory hair cells. EMBO Mol. Med. 6:984-992. http://dx.doi.org /10.15252/emmm.201403976

Petit, C., and G.P. Richardson. 2009. Linking genes underlying deafness to hairbundle development and function. Nat. Neurosci. 12:703-710. http://dx .doi.org/10.1038/nn.2330
Probst, F.J., R.A. Fridell, Y. Raphael, T.L. Saunders, A. Wang, Y. Liang, R.J. Morell, J.W. Touchman, R.H. Lyons, K. Noben-Trauth, et al. 1998. Correction of deafness in shaker-2 mice by an unconventional myosin in a BAC transgene. Science. 280:1444-1447. http://dx.doi.org/10.1126/ science.280.5368.1444

Prost, J., C. Barbetta, and J.-F. Joanny. 2007. Dynamical control of the shape and size of stereocilia and microvilli. Biophys. J. 93:1124-1133. http://dx.doi .org/10.1529/biophysj.106.098038

Rzadzinska, A.K., M.E. Schneider, C. Davies, G.P. Riordan, and B. Kachar. 2004. An actin molecular treadmill and myosins maintain stereocilia functional architecture and self-renewal. J. Cell Biol. 164:887-897. http://dx.doi.org/10.1083/jcb.200310055

Sahly, I., E. Dufour, C. Schietroma, V. Michel, A. Bahloul, I. Perfettini, E. Pepermans, A. Estivalet, D. Carette, A. Aghaie, et al. 2012. Localization of Usher 1 proteins to the photoreceptor calyceal processes, which are absent from mice. J. Cell Biol. 199:381-399. http://dx.doi.org /10.1083/jcb.201202012

Salles, F.T., R.C. Merritt Jr., U. Manor, G.W. Dougherty, A.D. Sousa, J.E. Moore, C.M. Yengo, A.C. Dosé, and B. Kachar. 2009. Myosin IIIa boosts elongation of stereocilia by transporting espin 1 to the plus ends of actin filaments. Nat. Cell Biol. 11:443-450. http://dx.doi.org/10.1038/ncb1851

Schneider, M.E., A.C. Dosé, F.T. Salles, W. Chang, F.L. Erickson, B. Burnside, and B. Kachar. 2006. A new compartment at stereocilia tips defined by spatial and temporal patterns of myosin IIIa expression. J. Neurosci. 26:10243-10252. http://dx.doi.org/10.1523/JNEUROSCI.2812-06.2006

Sekerková, G., L. Zheng, P.A. Loomis, B. Changyaleket, D.S. Whitlon, E. Mugnaini, and J.R. Bartles. 2004. Espins are multifunctional actin cytoskeletal regulatory proteins in the microvilli of chemosensory and mechanosensory cells. J. Neurosci. 24:5445-5456. http://dx.doi.org/10 .1523/JNEUROSCI.1279-04.2004

Sekerková, G., L. Zheng, E. Mugnaini, and J.R. Bartles. 2006. Differential expression of espin isoforms during epithelial morphogenesis, stereociliogenesis and postnatal maturation in the developing inner ear. Dev. Biol. 291:83-95. http://dx.doi.org/10.1016/j.ydbio.2005.12.021

Sekerková, G., C.-P. Richter, and J.R. Bartles. 2011. Roles of the espin actinbundling proteins in the morphogenesis and stabilization of hair cell stereocilia revealed in CBA/CaJ congenic jerker mice. PLoS Genet. 7:e1002032. http://dx.doi.org/10.1371/journal.pgen.1002032

Self, T., T. Sobe, N.G. Copeland, N.A. Jenkins, K.B. Avraham, and K.P. Steel. 1999. Role of myosin VI in the differentiation of cochlear hair cells. Dev. Biol. 214:331-341. http://dx.doi.org/10.1006/dbio.1999.9424

Shin, J.-B., J.F. Krey, A. Hassan, Z. Metlagel, A.N. Tauscher, J.M. Pagana, N.E. Sherman, E.D. Jeffery, K.J. Spinelli, H. Zhao, et al. 2013. Molecular architecture of the chick vestibular hair bundle. Nat. Neurosci. 16:365374. http://dx.doi.org/10.1038/nn.3312

Tarchini, B., C. Jolicoeur, and M. Cayouette. 2013. A molecular blueprint at the apical surface establishes planar asymmetry in cochlear hair cells. Dev. Cell. 27:88-102. http://dx.doi.org/10.1016/j.devcel.2013.09.011

Tilney, L.G., D.J. Derosier, and M.J. Mulroy. 1980. The organization of actin filaments in the stereocilia of cochlear hair cells. J. Cell Biol. 86:244-259. http://dx.doi.org/10.1083/jcb.86.1.244

Tilney, L.G., M.S. Tilney, and D.J. DeRosier. 1992. Actin filaments, stereocilia, and hair cells: how cells count and measure. Annu. Rev. Cell Biol. 8:257274. http://dx.doi.org/10.1146/annurev.cb.08.110192.001353

Walsh, T., V. Walsh, S. Vreugde, R. Hertzano, H. Shahin, S. Haika, M.K. Lee, M. Kanaan, M.-C. King, and K.B. Avraham. 2002. From flies' eyes to our ears: mutations in a human class III myosin cause progressive nonsyndromic hearing loss DFNB30. Proc. Natl. Acad. Sci. USA. 99:7518-7523. http://dx.doi.org/10.1073/pnas.102091699

Walsh, V.L., D. Raviv, A.A. Dror, H. Shahin, T. Walsh, M.N. Kanaan, K.B. Avraham, and M.-C. King. 2011. A mouse model for human hearing loss DFNB30 due to loss of function of myosin IIIA. Mamm. Genome. 22:170-177. http://dx.doi.org/10.1007/s00335-010-9310-6

Weil, D., S. Blanchard, J. Kaplan, P. Guilford, F. Gibson, J. Walsh, P. Mburu, A. Varela, J. Levilliers, M.D. Weston, et al. 1995. Defective myosin VIIA gene responsible for Usher syndrome type 1B. Nature. 374:60-61. http://dx.doi.org/10.1038/374060a0

Zhang, D.-S., V. Piazza, B.J. Perrin, A.K. Rzadzinska, J.C. Poczatek, M. Wang, H.M. Prosser, J.M. Ervasti, D.P. Corey, and C.P. Lechene. 2012. Multiisotope imaging mass spectrometry reveals slow protein turnover in hair-cell stereocilia. Nature. 481:520-524. http://dx.doi.org/10.1038/ nature 10745

Zheng, L., D.M. Beeler, and J.R. Bartles. 2014. Characterization and regulation of an additional actin-filament-binding site in large isoforms of the stereocilia actin-bundling protein espin. J. Cell Sci. 127:1306-1317. http://dx.doi.org/10.1242/jcs.143255 